OPEN ACCESS

Edited by:

Yi Wang,

Zhejiang University, China

Reviewed by:

José Blanco-Salas,

University of Extremadura, Spain Ambrose Okem,

University of the Witwatersrand,

South Africa

*Correspondence:

Luping Qin

Ipqin@zcmu.edu.cn

Bo Zhu

zhubo@zcmu.edu.cn

Specialty section:

This article was submitted to

Ethnopharmacology,

a section of the journal

Frontiers in Pharmacology

Received: 17 June 2021

Accepted: 26 July 2021

Published: 06 August 2021

Citation:

Chen W, Lu J, Zhang J, Wu J, Yu L,

Qin L and Zhu B (2021) Traditional

Uses, Phytochemistry, Pharmacology, and Quality Control of Dendrobium

officinale Kimura et. Migo.

Front. Pharmacol. 12:726528.

doi: 10.3389/fphar.2021.726528

\section{Traditional Uses, Phytochemistry, Pharmacology, and Quality Control of Dendrobium officinale Kimura et. Migo}

Wenhua Chen, Jiemiao Lu, Jiahao Zhang, Jianjun Wu, Lilong Yu, Luping Qin * and Bo Zhu*

School of Pharmaceutical Sciences, Zhejiang Chinese Medical University, Hangzhou, China

Dendrobium officinale, a well-known plant used as a medicinal and food homologous product, has been reported to contain various bioactive components, such as polysaccharides, bibenzyls, phenanthrenes, and flavonoids. It is also widely used as a traditional medicine to strengthen "Yin", nourish heart, tonify five viscera, remove arthralgia, relieve fatigue, thicken stomach, lighten body, and prolong life span. These traditional applications are in consistent with modern pharmacological studies, which have demonstrated that $D$. officinale exhibits various biological functions, such as cardioprotective, anti-tumor, gastrointestinal protective, anti-diabetes, immunomodulatory, anti-aging, and anti-osteoporosis effects. In this review, we summarize the research progress of D. officinale from November 2016 to May 2021 and aim to better understand the botany, traditional use, phytochemistry, and pharmacology of $D$. officinale, as well as its quality control and safety. This work presents the development status of $D$. officinale, analyzes gaps in the current research on $D$. officinale, and raises the corresponding solutions to provide references and potential directions for further studies of $D$. officinale.

Keywords: Dendrobium officinale, phytochemistry, pharmacology, quality control, traditional use

\section{INTRODUCTION}

The genus Dendrobium (Orchidaceae) includes more than 1,000 species (Teixeira and Ng, 2017). Among them, Dendrobium officinale Kimura et. Migo is a precious medicinal plant recorded in Chinese Pharmacopoeia, which is widely used as a traditional Chinese medicine (Editorial Board of China Pharmacopoeia Committee, 2020). Moreover, there is a synonym of "Dendrobium catenatum Lindl." in the plant list (http://ipni.org/urn:lsid:ipni.org:names:628140-1). It is well known that $D$. officinale is distributed in several countries around the world, such as the United States, Japan, and Australia. In particular, D. officinale exhibits a broader distribution in the different regions of China, including Anhui, Zhejiang, Hunan, Fujian, Guangxi, Sichuan, and Yunnan Provinces (Guo et al., 2020a). Due to the overexploitation and depletion of its wild plant resources, it has been considered as a secondary endangered plant in the "China Plant Red Data Book" (Fu, 1992). On the other hand, the artificial cultivation technology of $D$. officinale has made a significant breakthrough (Cheng Y et al., 2019). However, the existing cultivation resources of $D$. officinale are mixed, which results in the uneven product quality and the unsound evaluation system, greatly affecting the practical and reasonable development and utilization of $D$. officinale.

Pharmacological results published in the literature have revealed multiple promising bioactivities of D. officinale, including cardioprotective (Xiao et al., 2018), anti-tumor (Guo et al., 2019), gastrointestinal protective (Liu et al., 2020), anti-diabetes (Zeng et al., 2020), 


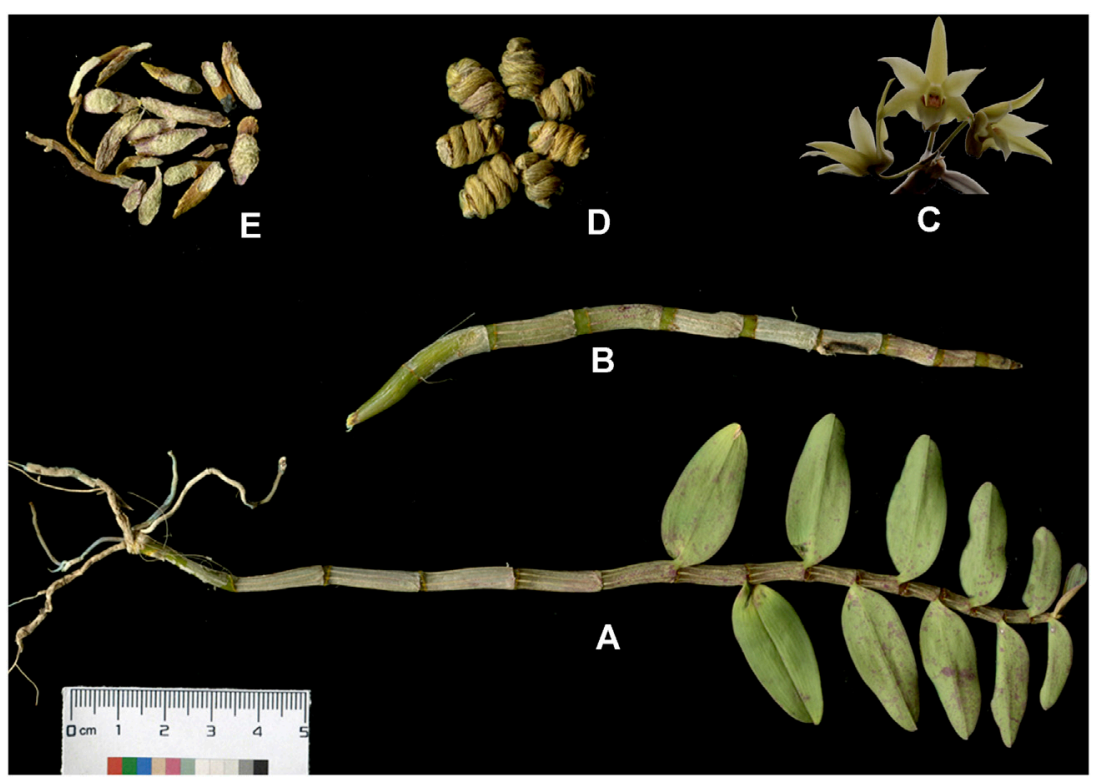

FIGURE 1 | The whole plant (A), fresh strips (B), flowers (C), commercial product named Tiepifengdou (D), and decoction pieces (E) of Dendrobium officinale Kimura et. Migo.

immunomodulatory (Huang et al., 2018), anti-aging (Liang et al., 2017), and anti-osteoporosis (Wang et al., 2018) effects. Besides, it is usually prescribed as one of the ingredients of herbal formula, such as "Tin maple crystal" (Tiepifengdoujing: D. officinale and American ginseng), for regulating the gastrointestinal tract in traditional and contemporary clinical practice (Qin et al., 2019). According to currently available phytochemical investigations, the bioactive chemical components of $D$. officinale mainly consist of polysaccharides (Zhao et al., 2019), bibenzyls (Zhao et al., 2020), phenanthrenes (Liu et al., 2019), flavonoids (Xing et al., 2018), and alkaloids (Chu et al., 2019). In contrast, according to the literature, only few of these compounds have been evaluated in bioactivity assays (Zhao et al., 2018a; Liu et al., 2018; Xing et al., 2018; Chu et al., 2019; Liu et al., 2019; Lee et al., 2020; Zhao et al., 2020). Additionally, although D. officinale is utilized as an effective matter to treat various diseases, its quality control and safety have yet to be defined.

The present review provides an up-to-date and comprehensive literature analysis of $D$. officinale on the basis of botany, traditional applications, phytochemistry, pharmacology, quality control, and safety, which may provide new insights into the development and applications of $D$. officinale as a novel therapeutic agent for the prevention and treatment of diseases.

\section{MATERIALS AND METHODS}

All the information available about $D$. officinale was obtained from scientific databases, including Web of Science, PubMed, Google Scholar, Baidu Scholar, Springer, Sci Finder, and ScienceDirect, CNKI, from November 2016 to May 2021, and classic books of Chinese herbal medicines. The keywords included Dendrobium officinale, Dendrobium catenatum, ethnopharmacology, phytochemistry, biological activity, pharmacology, clinic, traditional uses, safety, quality control, toxicology, and other related words. In this paper, $D$. catenatum was also written as D. officinale. However, the other species in Dendrobium genera were excluded.

\section{BOTANY}

According to the Chinese Pharmacopoeia (Editorial Board of China Pharmacopoeia Committee, 2020), D. officinale can be twisted into a spring or spiral shape, which can be further heated and dried to prepare Tiepifengdou. D. officinale typically has 2-6 whorls with a length of $3-12 \mathrm{~cm}$ and a diameter of $0.2-0.4 \mathrm{~cm}$ after straightening. The surface color of $D$. officinale is yellowgreen or light golden yellow, with fine longitudinal wrinkles, obvious nodes. Moreover, sometimes residual gray-white leaf sheaths can be seen on the nodes. The short fibrous roots remaining at the stem base can be observed at one end (Flora of China Editorial Committee, 2009). D. officinale is solid and fragile with a flat section while showing gray-white to gray-green color and slightly horny (Figure 1).

"Flora of China" records: D. officinale grows upright to a height of $9-35 \mathrm{~cm}$ and a thickness of $2-4 \mathrm{~mm}$ and is usually cylindrical. The stem is vertical without branches while having many nodes above the middle and 3-5 leaves alternate. The leaves are biseriate, papery, and oblong-lanceolate. The apex is obtuse and slightly hooked. The leaf-sheaths often exhibit purple spots. Its inflorescence racemes usually come from the upper part of old stems, with deciduous leaves and 2-3 flowers. The inflorescence axis is bent back and is $2-4 \mathrm{~cm}$ long. Sepals and petals show 
TABLE 1 | Summary of traditional medicinal uses of $D$. officinale.

Traditional use

Removing arthralgia, tonifying five viscera, relieving fatigue, strengthening Yin, thickening

stomach, lightening body, and prolonging life

Raw stone, fine and solid, color of gold, and the shape of grasshopper legs is better

Nourishing the essence, reinforcing kidney, calming stomach, building muscles, expeling evil heat, relieving foot and knee pain, and removing convulsion

Replenishing Qi and removing heat

Nourishing the essence, calming stomach, building muscles, expelling skin evil heat, relieving

foot and knee pain

Treating asthenia heat in stomach

Treating fever, spontaneous sweating, ulcer, and pus

Removing dampness of spleen and stomach

Treating deficiency of spleen and stomach, and relieve internal heat or fever

Invigorating spleen and kidney

Entering the spleen to remove deficiency heat and kidney astringency

Removing stomach deficiency heat and check polydipsia

\begin{tabular}{|c|c|}
\hline $\begin{array}{l}\text { Part } \\
\text { used }\end{array}$ & Ref. \\
\hline Stem & $\begin{array}{l}\text { Shennong's Herbal Classic (《神农本草经》) (Dong Han Dynasty, } \\
\text { A.D. 25-220) }\end{array}$ \\
\hline Stem & $\begin{array}{l}\text { Variorum of Classic of Herbology (《本草经集注》》) (Liang } \\
\text { Dynasty, A.D. 502-557) }\end{array}$ \\
\hline Stem & $\begin{array}{l}\text { Records of Famous Doctors (《名医别录》》) (Weijin Dynasty, A.D. } \\
\text { 220-450) }\end{array}$ \\
\hline Stem & Theory of Property (〈药性论》》) (Tang Dynasty, A.D. 618-907) \\
\hline Stem & $\begin{array}{l}\text { Herbal Medicines for Kaibao (《开宝本草》) (Song Dynasty, A.D. } \\
\text { 960-1,279) }\end{array}$ \\
\hline Stem & $\begin{array}{l}\text { Amplified Herbology (《本草衍义》) (Song Dynasty, A.D. } \\
\text { 960-1,127) }\end{array}$ \\
\hline Stem & $\begin{array}{l}\text { Compendium of Herbology (〈本草纲目 }\rangle) \text { (Ming Dynasty, A.D. } \\
1,552-1,578)\end{array}$ \\
\hline Stem & Herbal classics (《本草经疏》》) (Ming Dynasty, A.D. 1,552-1,578) \\
\hline Stem & $\begin{array}{l}\text { Herbal Medicines for Mengquan (《本草蒙荃 }\rangle)(\text { Ming Dynasty, } \\
\text { A.D. 1,552-1,578) }\end{array}$ \\
\hline Stem & Essential Herbs (《本草备要》) (Qing Dynasty, A.D. 1,636-1912) \\
\hline Stem & $\begin{array}{l}\text { Herbal Medicines for Qiuzhen (《〈本草求真〉》) (Qing Dynasty, A.D. } \\
\text { 1,636-1912) }\end{array}$ \\
\hline Stem & Match Medica (《得配本草》) (Qing Dynasty, A.D. 1,636-1912) \\
\hline
\end{tabular}

yellow-green color and comparable sizes, which are usually endrounded and have five veins (Flora of China Editorial Committee, 2009). The flowering period is from March to June (Zhao et al., 2018a; Liu et al., 2018).

D. officinale is well-known for its nutritional and medicinal value (Flora of China Editorial Committee, 2009), which often grows in semi-humid mountain rocks over $1,600 \mathrm{~m}$ and is widely distributed in Anhui, Zhejiang, Fujian, Guangxi, Sichuan, Yunnan Provinces in China. Moreover, D. officinale displays a broad geographical distribution in other countries or regions, including India, Australia, Japan, and United States (Guo et al., 2020a).

\section{TRADITIONAL USES}

D. officinale is mainly used as traditional medicine and healthy food in China. D. officinale was initially recorded in "Shennong's Herbal Classic” (《神农本草经》, Dong Han Dynasty, A.D. 25-220), which has the ability to strengthen "Yin", tonify five viscera, nourish heart, remove arthralgia, relieve fatigue, thicken stomach, lighten the body, and prolong life span. In "Variorum of Classic of Herbology” (《本草经集注》, Liang Dynasty, A.D. 502-557), the appearance of $D$. officinale was mentioned to be rough, fine, and solid with a golden color. Moreover, the quality is better if the shape is like grasshopper legs. In "Records of Famous Doctors” (《名医别录》, Weijin Dynasty, A.D. 220-450), D. officinale was recorded to be non-toxic and could be widely used to nourish the essence, reinforce kidney, calm the stomach, build muscles, expel evil heat, relieve foot and knee pain, and remove convulsion. In “Theory of Property” (《药性 论》》, Tang Dynasty, A.D. 618-907), it was stated that D. officinale could replenish "Qi" and remove heat. Moreover, Herbal Medicines for Kaibao (《开宝本草》, Song Dynasty, A.D.
960-1,279) also had similar description regarding the medical benefits of $D$. officinale as described above. In addition, it was also recorded in “Amplified Herbology” (《本草衍义》, Song Dynasty, A.D. 960-1,127) that D. officinale could treat asthenia heat in the stomach. In “Compendium of Herbology” (《本草纲目》, Ming Dynasty, A.D. 1,552-1,578), D. officinale was described as a therapeutic approach for fever, spontaneous sweating, ulcer, and pus. According to the record in "Herbal classics" (《本草 经疏》》, Ming Dynasty, A.D. 1,552-1,578), D. officinale shows the function to remove dampness of spleen and stomach. It was reported that $D$. officinale could treat deficiency of spleen and stomach and relieve internal heat or fever in "Herbal Medicines for Mengquan” (《本草蒙荃〉, Ming Dynasty, A.D. 1,552-1,578). In “Essential Herbs” (《本草备要》, Qing Dynasty, A.D. 1,636-1,912), it was documented that D. officinale could invigorate spleen and kidney. Similarly, in "Herbal Medicines for Qiuzhen” (《本草求真》》, Qing Dynasty, A.D. 1,636-1,912), it was registered that $D$. officinale has the ability to enter the spleen to remove deficiency heat and kidney astringency. Additionally, it was recorded that $D$. officinale could mitigate stomach deficiency and heat (inflammation) and check for polydipsia in "Match Medica” (《得配本草》, Qing Dynasty, A.D. 1,636-1,912). The summary of the traditional medicinal uses is shown in Table 1.

D. officinale has been reported to have effects on benefiting heart and stomach to produce saliva and nourishing "Yin" to clear heat in China Pharmacopoeia Committee, which is mainly utilized in the treatment of fluid injury, deficiency of "Yin" in the heart and stomach, no regression of inflammation after the disease, hyperactivity of heat due to "Yin" deficiency, dark eyes, muscles, and bone weakness in accordance with China Pharmacopoeia Committee (Committee for the Pharmacopoeia of PR China, 2015). On the other hand, D. officinale stems can be used as ordinary food (National Health and Family Planning Commission of the People's Republic of 
TABLE 2 | The main compounds isolated from $D$. officinale.

\begin{tabular}{|c|c|c|c|c|c|}
\hline Class & No & Name & Formula & Plant parts & Ref. \\
\hline \multirow[t]{22}{*}{ Bibenzyls } & 1 & 4,4'-Dihydroxy-3,5-dimethoxybibenzyl & $\mathrm{C}_{16} \mathrm{H}_{18} \mathrm{O}_{4}$ & Leaves & Ren et al. (2020a); Ren et al. (2020b) \\
\hline & 2 & 3,4'-Dihydroxy-5-methoxybibenzyl & $\mathrm{C}_{15} \mathrm{H}_{16} \mathrm{O}_{3}$ & Stems & Liu et al. (2018) \\
\hline & 3 & 3,4-Dihydroxy-4',5-dimethoxybibenzyl & $\mathrm{C}_{16} \mathrm{H}_{18} \mathrm{O}_{4}$ & Leaves & Ren et al. (2020a); Ren et al. (2020b) \\
\hline & 4 & Gigantol & $\mathrm{C}_{16} \mathrm{H}_{18} \mathrm{O}_{4}$ & Stems, Leaves & He et al. (2020); Ren et al. (2020b) \\
\hline & 5 & Moscatilin & $\mathrm{C}_{17} \mathrm{H}_{20} \mathrm{O}_{5}$ & Leaves & Ren et al. (2020a); Ren et al. (2020b) \\
\hline & 6 & Tristin & $\mathrm{C}_{15} \mathrm{H}_{16} \mathrm{O}_{4}$ & Stems & He et al. (2020) \\
\hline & 7 & Erianin & $\mathrm{C}_{18} \mathrm{H}_{22} \mathrm{O}_{5}$ & Stems & Peng et al. (2020) \\
\hline & 8 & 3,4,4'-Trihydroxy-5-methoxybibenzyl & $\mathrm{C}_{15} \mathrm{H}_{16} \mathrm{O}_{4}$ & Stems & Chu et al. (2019) \\
\hline & 9 & 3-Hydroxy-4',5-dimethoxybibenzy & $\mathrm{C}_{16} \mathrm{H}_{18} \mathrm{O}_{3}$ & Stems & Chu et al. (2019) \\
\hline & 10 & Amoenylin & $\mathrm{C}_{17} \mathrm{H}_{20} \mathrm{O}_{4}$ & Stems & Chu et al. (2019) \\
\hline & 11 & Dendrophenol & $\mathrm{C}_{17} \mathrm{H}_{20} \mathrm{O}_{5}$ & Stems & Peng et al. (2020) \\
\hline & 12 & Dihydroresveratrol & $\mathrm{C}_{14} \mathrm{H}_{14} \mathrm{O}_{3}$ & Stems & Liu et al. (2018) \\
\hline & 13 & Dendrocandin B & $\mathrm{C}_{27} \mathrm{H}_{30 O}$ & Leaves & Ren et al. (2020a); Ren et al. (2020b) \\
\hline & 14 & Denofficin & $\mathrm{C}_{36} \mathrm{H}_{38} \mathrm{O}_{10}$ & Leaves & Ren et al. (2020b) \\
\hline & 15 & Dendrocandin U & $\mathrm{C}_{26} \mathrm{H}_{28} \mathrm{O}_{8}$ & Stems, Leaves & $\begin{array}{l}\text { Liu et al. (2018); Ren et al. (2020a); Ren et al. } \\
\text { (2020b) }\end{array}$ \\
\hline & 16 & Dendrocandin W & $\mathrm{C}_{26} \mathrm{H}_{28} \mathrm{O}_{8}$ & Stems & Zhu et al. (2020) \\
\hline & 17 & Dendrocandin V & $\mathrm{C}_{26} \mathrm{H}_{28} \mathrm{O}_{7}$ & Stems & Zhu et al. (2020) \\
\hline & 18 & Trigonopol B & $\mathrm{C}_{25} \mathrm{H}_{26} \mathrm{O}_{7}$ & Stems & Zhu et al. (2020) \\
\hline & 19 & 3,4, a-Trihydroxy-5,4'-dimethoxybibenzyl & $\mathrm{C}_{16} \mathrm{H}_{18} \mathrm{O}_{5}$ & Laves & Ren et al. (2020a); Ren et al. (2020b) \\
\hline & 20 & Dendrocandin N & $\mathrm{C}_{25} \mathrm{H}_{26} \mathrm{O}_{7}$ & Stems & Zhu et al. (2020) \\
\hline & 21 & Dendrocandin P1 & $\mathrm{C}_{26} \mathrm{H}_{24} \mathrm{O}_{8}$ & Stems & He et al. (2020) \\
\hline & 22 & Dendrocandin P2 & $\mathrm{C}_{26} \mathrm{H}_{26} \mathrm{O}_{8}$ & Stems & He et al. (2020) \\
\hline \multirow[t]{6}{*}{ Phenanthrenes } & 23 & Ephemeranthol A & $\mathrm{C}_{16} \mathrm{H}_{16} \mathrm{O}_{4}$ & Stems & Cui et al. (2019); He et al. (2020) \\
\hline & 24 & Erianthridin & $\mathrm{C}_{16} \mathrm{H}_{16} \mathrm{O}_{4}$ & Stems & Cui et al. (2019) \\
\hline & 25 & Orchinol & $\mathrm{C}_{15} \mathrm{H}_{14} \mathrm{O}_{3}$ & Stems & He et al. (2020) \\
\hline & 26 & 2,4,7-Trihydroxy-9, 10-dihydrophenanthrene & $\mathrm{C}_{14} \mathrm{H}_{12} \mathrm{O}_{3}$ & Stems & He et al. (2020) \\
\hline & 27 & Confusarin & $\mathrm{C}_{17} \mathrm{H}_{16} \mathrm{O}_{5}$ & Stems & Cui et al. (2019); He et al. (2020) \\
\hline & 28 & 2,7-Dihydroxy-3, 4-dimethoxyphenanthrene & $\mathrm{C}_{16} \mathrm{H}_{14} \mathrm{O}_{4}$ & Stems & Cui et al. (2019) \\
\hline \multirow[t]{16}{*}{ Penylpropanoids } & 29 & 1-O-Caffeoyl- $\beta$-D-glucoside & $\mathrm{C}_{15} \mathrm{H}_{18} \mathrm{O}_{9}$ & Flowers & Zhang et al. (2019) \\
\hline & 30 & 1-O-p-Coumaroyl- $\beta$-D-glucoside & $\mathrm{C}_{15} \mathrm{H}_{18} \mathrm{O}_{8}$ & Flowers & Zhang et al. (2019) \\
\hline & 31 & ethyl $p$-Hydroxyhydrocinnamate & $\mathrm{C}_{11} \mathrm{H}_{14} \mathrm{O}_{3}$ & Leaves & Ren et al. (2020a) \\
\hline & 32 & $\omega$-Hydroxypropioguaiacone & $\mathrm{C}_{10} \mathrm{H}_{12} \mathrm{O}_{4}$ & Stems & Zhu et al. (2020) \\
\hline & 33 & trans-3,4,5-Trimethoxyl-cinnamyl alcohol & $\mathrm{C}_{12} \mathrm{H}_{16} \mathrm{O}_{4}$ & Stems & Cui et al. (2019) \\
\hline & 34 & Dihydroconiferyldihydro- $p$-coumarate & $\mathrm{C}_{19} \mathrm{H}_{22} \mathrm{O}_{5}$ & Stems & Ye et al. (2017) \\
\hline & 35 & 6-Hydroxy-3-oxo-a-ionol & $\mathrm{C}_{13} \mathrm{H}_{20} \mathrm{O}_{3}$ & Stems & Zhu et al. (2020) \\
\hline & 36 & Scoparone & $\mathrm{C}_{11} \mathrm{H}_{10} \mathrm{O}_{4}$ & Stems & Peng et al. (2020) \\
\hline & 37 & Syringaresinol & $\mathrm{C}_{22} \mathrm{H}_{26} \mathrm{O}_{8}$ & Stems, Leaves & Ye et al. (2017); Ren et al. (2020a) \\
\hline & 38 & Magnolenin C & $\mathrm{C}_{28} \mathrm{H}_{36} \mathrm{O}_{14}$ & Stems & Cui et al. (2019) \\
\hline & 39 & Officinalioside & $\mathrm{C}_{28} \mathrm{H}_{34} \mathrm{O}_{14}$ & Stems & Cui et al. (2019) \\
\hline & 40 & Moellenoside A & $\mathrm{C}_{26} \mathrm{H}_{32} \mathrm{O}_{11}$ & Stems & Cui et al. (2019) \\
\hline & 41 & Pinoresinol-4-O- $\beta$-D-glucopyranoside & $\mathrm{C}_{28} \mathrm{H}_{36} \mathrm{O}_{14}$ & Stems & Cui et al. (2019) \\
\hline & 42 & 5, 5'-Dimethoxy-lariciresinol & $\mathrm{C}_{23} \mathrm{H}_{30} \mathrm{O}_{8}$ & Stems & He et al. (2020) \\
\hline & 43 & Lyoniresinol & $\mathrm{C}_{22} \mathrm{H}_{28} \mathrm{O}_{8}$ & Stems & He et al. (2020) \\
\hline & 44 & (+)-Syringaresinol-4'-O- $\beta$-D-glucopyranoside & $\mathrm{C}_{28} \mathrm{H}_{36} \mathrm{O}_{13}$ & Stems & Chen et al. (2018) \\
\hline \multirow[t]{17}{*}{ Flavonoids } & 45 & Apigenin & $\mathrm{C}_{15} \mathrm{H}_{10} \mathrm{O}_{5}$ & Roots, Stems, Leaves & Yu et al. (2018); Ren et al. (2020c) \\
\hline & 46 & Naringenin & $\mathrm{C}_{15} \mathrm{H}_{12} \mathrm{O}_{5}$ & Stems & Ye et al. (2017); Peng et al. (2020) \\
\hline & 47 & Naringin & $\mathrm{C}_{27} \mathrm{H}_{32} \mathrm{O}_{14}$ & Stems & Zhou et al. (2018) \\
\hline & 48 & 2-Hydroxynaringenin & $\mathrm{C}_{15} \mathrm{H}_{12} \mathrm{O}_{6}$ & Roots, Stems, Laves & Ren et al. (2020c) \\
\hline & 49 & Phloretin & $\mathrm{C}_{15} \mathrm{H}_{14} \mathrm{O}_{5}$ & Roots, Stems & Ren et al. (2020c) \\
\hline & 50 & Eriodictyol & $\mathrm{C}_{15} \mathrm{H}_{12} \mathrm{O}_{6}$ & Stems & Lv et al. (2017) \\
\hline & 51 & Chrysoeriol & $\mathrm{C}_{16} \mathrm{H}_{12} \mathrm{O}_{6}$ & Stems & Lv et al. (2017) \\
\hline & 52 & Quercetin & $\mathrm{C}_{15} \mathrm{H}_{10} \mathrm{O}_{7}$ & Stems & Lv et al. (2017) \\
\hline & 53 & Taxifolin & $\mathrm{C}_{15} \mathrm{H}_{12} \mathrm{O}_{7}$ & Stems & Lv et al. (2017) \\
\hline & 54 & Isorhamnetin & $\mathrm{C}_{16} \mathrm{H}_{12} \mathrm{O}_{7}$ & Stems & Lv et al. (2017) \\
\hline & 55 & Rutin & $\mathrm{C}_{27} \mathrm{H}_{30} \mathrm{O}_{16}$ & $\begin{array}{l}\text { Stems, Leaves, } \\
\text { Flowers }\end{array}$ & $\begin{array}{l}\text { Ye et al. (2017); Zhou et al. (2018); Ren et al. } \\
\text { (2020a); Zhang et al. (2019) }\end{array}$ \\
\hline & 56 & Cosmosiin & $\mathrm{C}_{21} \mathrm{H}_{20} \mathrm{O}_{10}$ & Flowers & Ren et al. (2020c) \\
\hline & 57 & Genistin 7-O-gentiobioside & $\mathrm{C}_{27} \mathrm{H}_{30} \mathrm{O}_{15}$ & Stems & Yu et al. (2018) \\
\hline & 58 & Pelargonidin 3,5-O-diglucoside & $\mathrm{C}_{27} \mathrm{H}_{31} \mathrm{O}_{15}$ & Stems & Yu et al. (2018) \\
\hline & 59 & Pelargonidin 3-O-rutinoside & $\mathrm{C}_{27} \mathrm{H}_{31} \mathrm{O}_{14}$ & Stems & Yu et al. (2018) \\
\hline & 60 & Malvidin 3-O-glucosid & $\mathrm{C}_{23} \mathrm{H}_{25} \mathrm{O}_{12}$ & Stems & Yu et al. (2018) \\
\hline & 61 & Vicenin I & $\mathrm{C}_{26} \mathrm{H}_{28} \mathrm{O}_{14}$ & $\begin{array}{l}\text { Roots, Stems, } \\
\text { Leaves, Flowers }\end{array}$ & $\begin{array}{l}\text { Ye et al. (2017); Ren et al. (2020c); Zhang et al. } \\
\text { (2017b) }\end{array}$ \\
\hline
\end{tabular}

(Continued on following page) 
TABLE 2 | (Continued) The main compounds isolated from D. officinale.

\begin{tabular}{|c|c|c|c|c|c|}
\hline Class & No & Name & Formula & Plant parts & Ref. \\
\hline & 62 & Vicenin ॥ & $\mathrm{C}_{27} \mathrm{H}_{30} \mathrm{O}_{15}$ & $\begin{array}{l}\text { Roots, Stems, } \\
\text { Leaves, Flowers }\end{array}$ & $\begin{array}{l}\text { Lv et al. (2017); Zhang et al. (2017b); Luo et al. } \\
\text { (2019) }\end{array}$ \\
\hline & 63 & Vicenin III & $\mathrm{C}_{26} \mathrm{H}_{28} \mathrm{O}_{14}$ & Stems & Lei et al. (2018) \\
\hline & 64 & Violanthin & $\mathrm{C}_{27} \mathrm{H}_{30} \mathrm{O}_{14}$ & Stems & (Ye et al. 2017; Lei et al. 2018; Zhou et al. 2018) \\
\hline & 65 & Isoschaftoside & $\mathrm{C}_{26} \mathrm{H}_{28} \mathrm{O}_{14}$ & Stems, Flowers & $\begin{array}{l}\text { Ye et al. (2017); Zhou et al. (2018); Zhang et al. } \\
\text { (2019) }\end{array}$ \\
\hline & 66 & Schaftoside & $\mathrm{C}_{26} \mathrm{H}_{28} \mathrm{O}_{14}$ & Stems, Flowers & $\begin{array}{l}\text { Ye et al. (2017); Zhou et al. (2018); Zhang et al. } \\
\text { (2019) }\end{array}$ \\
\hline & 67 & Vitexin-2"-O- $\beta$-D-glucopyranoside & $\mathrm{C}_{26} \mathrm{H}_{27} \mathrm{O}_{14}$ & Stems & Ye et al. (2017) \\
\hline & 68 & Isovitexin apigenin-6-C-glucoside & $\mathrm{C}_{21} \mathrm{H}_{20} \mathrm{O}_{10}$ & Stems & Ren et al. (2020c) \\
\hline & 69 & Apigenin-6-C- $\beta$-D-xyloside-8-C- $\beta$-D-arabinoside & $\mathrm{C}_{25} \mathrm{H}_{26} \mathrm{O}_{13}$ & Stems & Ye et al. (2017) \\
\hline & 70 & Apigenin-6,8-di-C- $\alpha$-L-arabinoside & $\mathrm{C}_{25} \mathrm{H}_{26} \mathrm{O}_{13}$ & Stems, Flowers & Ye et al. (2017); Zhang et al. (2019) \\
\hline & 71 & Isoviolanthin & $\mathrm{C}_{27} \mathrm{H}_{30} \mathrm{O}_{14}$ & Stems, Leaves & Ye et al. (2017); Zhang et al. (2019) \\
\hline & 72 & Apigenin-6-C- $\alpha-L$-arabinoside-8-C- $\beta$-D-xyloside & $\mathrm{C}_{25} \mathrm{H}_{26} \mathrm{O}_{13}$ & Stems & Ye et al. (2017) \\
\hline & 73 & $\begin{array}{l}\left.\text { Apigenin-6-C-( } 2^{\prime \prime}-O-\beta-D g l u c o p y r a n o s i d e\right)-\alpha-L- \\
\text { arabinoside }\end{array}$ & $\mathrm{C}_{26} \mathrm{H}_{27} \mathrm{O}_{13}$ & Stems & Ye et al. (2017) \\
\hline & 74 & Neoschaftoside & $\mathrm{C}_{26} \mathrm{H}_{28} \mathrm{O}_{14}$ & Flowers & Zhang et al. (2019) \\
\hline & 75 & Vitexin-2"-O-glucoside & $\mathrm{C}_{27} \mathrm{H}_{30} \mathrm{O}_{15}$ & Flowers & Zhang et al. (2019) \\
\hline & 76 & Apigenin-6,8-di-C- $\beta$-D-glucoside & $\mathrm{C}_{27} \mathrm{H}_{30} \mathrm{O}_{15}$ & Flowers & Zhou et al. (2018); Zhang et al. (2019) \\
\hline & 77 & Apigenin-8-C- $\beta$-D-glucosyl-( $1 \rightarrow 4)-O-\beta$-D-glucoside & $\mathrm{C}_{27} \mathrm{H}_{30} \mathrm{O}_{15}$ & Flowers & Zhang et al. (2019) \\
\hline & 78 & Apigenin-6-C- $\beta$-D-xyloside-8-C- $\alpha$-L-arabinoside & $\mathrm{C}_{25} \mathrm{H}_{26} \mathrm{O}_{13}$ & Flowers & Zhang et al. (2019) \\
\hline & 79 & Apigenin-6-C- $\alpha$-L-arabinoside-8-C- $\beta$-D-xyloside & $\mathrm{C}_{25} \mathrm{H}_{26} \mathrm{O}_{13}$ & Flowers & Zhang et al. (2019) \\
\hline & 80 & Apigenin-6-C- $\alpha$-L-rhamnoside-8-C- $\beta$-D-xyloside & $\mathrm{C}_{26} \mathrm{H}_{28} \mathrm{O}_{13}$ & Flowers & Zhang et al. (2019) \\
\hline & 81 & Apigenin-6-C-arabinosyl-2"-O- $\beta$-D-glucoside & $\mathrm{C}_{26} \mathrm{H}_{28} \mathrm{O}_{14}$ & Flowers & Zhang et al. (2019) \\
\hline & 82 & Apigenin-8-C-glucosyl-(1 $\rightarrow 2)-a$-L-arabinoside & $\mathrm{C}_{26} \mathrm{H}_{28} \mathrm{O}_{14}$ & Flowers & Zhang et al. (2019) \\
\hline & 83 & Apigenin 6-C-glucosyl-(1 $\rightarrow 2)-\alpha$-L- arabinoside & $\mathrm{C}_{26} \mathrm{H}_{28} \mathrm{O}_{14}$ & Leaves & Zhang et al. (2017b) \\
\hline & 84 & Apigenin-6-C- $\beta$-D-xyloside-8-C- $\beta$-D-glucoside & $\mathrm{C}_{26} \mathrm{H}_{28} \mathrm{O}_{15}$ & Leaves & Zhou et al. (2018) \\
\hline & 85 & Apigenin-6-C- $\beta$-D-glucoside-8-C- $\beta$-D-xyloside & $\mathrm{C}_{26} \mathrm{H}_{28} \mathrm{O}_{15}$ & Leaves & Zhou et al. (2018) \\
\hline & 86 & Isoquercitrin & $\mathrm{C}_{21} \mathrm{H}_{20} \mathrm{O}_{12}$ & Flowers & Zhang et al. (2019) \\
\hline & 87 & Kaempferol-3-O- $\alpha$-L-rutinoside & $\mathrm{C}_{27} \mathrm{H}_{30} \mathrm{O}_{15}$ & Flowers & Zhang et al. (2019) \\
\hline & 88 & Kaempferol-3-O- $\beta$-D-glucoside & $\mathrm{C}_{21} \mathrm{H}_{20} \mathrm{O}_{11}$ & Flowers & Zhang et al. (2019) \\
\hline & 89 & Isorhamnetin-3-O- $\beta$-D-glucoside & $\mathrm{C}_{22} \mathrm{H}_{22} \mathrm{O}_{12}$ & Flowers & Zhang et al. (2019) \\
\hline & 90 & Tamarixin & $\mathrm{C}_{22} \mathrm{H}_{22} \mathrm{O}_{12}$ & Flowers & Zhang et al. (2019) \\
\hline & 91 & Nothofagin Glc & $\mathrm{C}_{21} \mathrm{H}_{24} \mathrm{O}_{10}$ & Flowers & Ren et al. (2020c) \\
\hline & 92 & $3^{\prime}, 5^{\prime}$-Di-C-glucosylphloretin & $\mathrm{C}_{27} \mathrm{H}_{34} \mathrm{O}_{15}$ & Stems & Ren et al. (2020c) \\
\hline & 93 & Cyanidin 3-O-rutinoside & $\mathrm{C}_{27} \mathrm{H}_{31} \mathrm{O}_{15}$ & Stems & Ren et al. (2020d) \\
\hline & 94 & Cyanidin 3-O-glucoside & $\mathrm{C}_{21} \mathrm{H}_{21} \mathrm{O}_{11}$ & Stems & Yu et al. (2018) \\
\hline & 95 & Cyanidin 3-O-galactoside & $\mathrm{C}_{21} \mathrm{H}_{21} \mathrm{O}_{11}$ & Stems & Yu et al. (2018) \\
\hline & 96 & Cyanidin 3-[6-(sinapoyl) glucoside]-5-glucoside & $\mathrm{C}_{38} \mathrm{H}_{41} \mathrm{O}_{20}$ & Stems & Ren et al. (2020d) \\
\hline & 97 & $\begin{array}{l}\text { Cyanidin 3-[2-(glucosyl)-6-(sinapoyl) glucoside]-5- } \\
\text { glucoside }\end{array}$ & $\mathrm{C}_{44} \mathrm{H}_{51} \mathrm{O}_{25}$ & Stems & Ren et al. (2020d) \\
\hline & 98 & $\begin{array}{l}\text { Cyanidin 3-[6-sinapoyl-2-O-(2-(sinapoyl) glucosyl)- } \\
\text { glucoside] }\end{array}$ & $\mathrm{C}_{49} \mathrm{H}_{51} \mathrm{O}_{24}$ & Stems & Ren et al. (2020d) \\
\hline & 99 & $\begin{array}{l}\text { Cyanidin 3-[6-sinapoyl-2-O-(2-(sinapoyl) glucosyl)- } \\
\text { glucoside]-5-glucoside }\end{array}$ & $\mathrm{C}_{55} \mathrm{H}_{61} \mathrm{O}_{29}$ & Stems & Ren et al. (2020d) \\
\hline & 100 & Cyanidin 3-[6-(sinapoyl)glucoside] & $\mathrm{C}_{32} \mathrm{H}_{31} \mathrm{O}_{15}$ & Stems & Ren et al. (2020d) \\
\hline & 101 & $\begin{array}{l}\text { Delphinidin 3-glucoside-7, 3'-di-[6-(sinapoyl) } \\
\text { glucoside] }\end{array}$ & $\mathrm{C}_{55} \mathrm{H}_{61} \mathrm{O}_{30}$ & Stems & Ren et al. (2020d) \\
\hline & 102 & Delphinidin 3,5-O-diglucoside & $\mathrm{C}_{27} \mathrm{H}_{31} \mathrm{O}_{17}$ & Stems & Yu et al. (2018) \\
\hline & 103 & Peonidin 3,5-O-diglucoside & $\mathrm{C}_{28} \mathrm{H}_{33} \mathrm{O}_{16}$ & Stems & Yu et al. (2018) \\
\hline \multirow[t]{5}{*}{ Alkaloids } & 104 & Anosmine & $\mathrm{C}_{11} \mathrm{H}_{17} \mathrm{~N}_{2}$ & Stems & Chen et al. (2018) \\
\hline & 105 & 2-Benzothiazolol & $\mathrm{C}_{7} \mathrm{H}_{5} \mathrm{NOS}$ & Leaves & Ren et al. (2020a) \\
\hline & 106 & 3,5-Dimethoxyphenethylamines & $\mathrm{C}_{10} \mathrm{H}_{15} \mathrm{NO}_{2}$ & Stems & Zhu et al. (2020) \\
\hline & 107 & $\mathrm{~N}-p$-coumaroyltyramine & $\mathrm{C}_{17} \mathrm{H}_{17} \mathrm{NO}_{3}$ & Stems & Chu et al. (2019) \\
\hline & 108 & $\mathrm{~N}$-trans-p-feruloyltyramine & $\mathrm{C}_{18} \mathrm{H}_{19} \mathrm{NO}_{4}$ & Stems & Chu et al. (2019) \\
\hline \multirow[t]{8}{*}{ Acids } & 109 & Malic acid & $\mathrm{C}_{4} \mathrm{H}_{6} \mathrm{O}_{5}$ & Stems & Chen et al. (2018) \\
\hline & 110 & Ferulic acid & $\mathrm{C}_{10} \mathrm{H}_{10} \mathrm{O}_{4}$ & Stems & Ye et al. (2017) \\
\hline & 111 & Vanillic acid & $\mathrm{C}_{8} \mathrm{H}_{8} \mathrm{O}_{4}$ & Stems & Ye et al. (2017) \\
\hline & 112 & Syringic acid & $\mathrm{C}_{9} \mathrm{H}_{10} \mathrm{O}_{5}$ & Stems & Ye et al. (2017) \\
\hline & 113 & Protocatechuic acid & $\mathrm{C}_{7} \mathrm{H}_{6} \mathrm{O}_{4}$ & Leaves & Ren et al. (2020a) \\
\hline & 114 & $p$-Hydroxycinnamic acid & $\mathrm{C}_{9} \mathrm{H}_{8} \mathrm{O}_{3}$ & Stems & Ye et al. (2017) \\
\hline & 115 & p-Hydroxylbenzoic acid & $\mathrm{C}_{7} \mathrm{H}_{6} \mathrm{O}_{3}$ & Leaves & Ren et al. (2020a) \\
\hline & 116 & Palmitic acid & $\mathrm{C}_{16} \mathrm{H}_{32} \mathrm{O}_{2}$ & Leaves & Ren et al. (2020a) \\
\hline
\end{tabular}

(Continued on following page) 
TABLE 2 | (Continued) The main compounds isolated from D. officinale.

\begin{tabular}{|c|c|c|c|c|c|}
\hline Class & No & Name & Formula & Plant parts & Ref. \\
\hline \multirow[t]{10}{*}{ Others } & 117 & Flifimdioside A & $\mathrm{C}_{32} \mathrm{H}_{52} \mathrm{O}_{13}$ & Stems & Chen et al. (2018) \\
\hline & 118 & Flickinflimoside B & $\mathrm{C}_{31} \mathrm{H}_{50} \mathrm{O}_{13}$ & Stems & Chen et al. (2018) \\
\hline & 119 & Loliolide & $\mathrm{C}_{11} \mathrm{H}_{16} \mathrm{O}_{3}$ & Leaves & Ren et al. (2020a) \\
\hline & 120 & 1-Glycerol linolenate & $\mathrm{C}_{21} \mathrm{H}_{36} \mathrm{O}_{4}$ & Leaves & Ren et al. (2020a) \\
\hline & 121 & Densiflorol A & $\mathrm{C}_{16} \mathrm{H}_{16} \mathrm{O}_{4}$ & Leaves & Ren et al. (2020a); Ren et al. (2020b) \\
\hline & 122 & 2-Butoxyethyl linolenate & $\mathrm{C}_{24} \mathrm{H}_{42} \mathrm{O}_{3}$ & Leaves & Ren et al. (2020a) \\
\hline & 123 & Catechol & $\mathrm{C}_{6} \mathrm{H}_{6} \mathrm{O}_{2}$ & Leaves & Ren et al. (2020a) \\
\hline & 124 & Octadecadienoic acid-2,3-dihydroxypropyl ester & $\mathrm{C}_{21} \mathrm{H}_{40} \mathrm{O}_{4}$ & Leaves & Ren et al. (2020a) \\
\hline & 125 & Stigmast-5-en-3 $\beta$-ol-7-one & $\mathrm{C}_{29} \mathrm{H}_{48} \mathrm{O}_{2}$ & Stems & Zhu et al. (2020) \\
\hline & 126 & Dendrofindlaphenol B & $\mathrm{C}_{27} \mathrm{H}_{30} \mathrm{O}_{6}$ & Stems & Liu et al. (2018) \\
\hline
\end{tabular}

China, 2013). In traditional Chinese therapies, D. officinale is often combined with other Chinese herbal medicines, including Adenophora stricta, Ophiopogon japonicus, Paeonia lactiflora, Astragalus membranaceus and Polygonatum odoratum. In recent years, pharmacological research mainly focused on the cardioprotective (Xiao et al., 2018), anti-tumor (Guo et al., 2019), gastrointestinal protective (Liu et al., 2020), and anti-diabetes (Zeng et al., 2020) effects of D. officinale. Therefore, it is encouraged to combine the traditional pharmacological actions of $D$. officinale and advanced research technologies in order to explore the potential mechanisms and establish the foundation for its clinical applications in the future.

\section{PHYTOCHEMISTRY}

Extensive phytochemistry studies have demonstrated that $D$. officinale mainly contains polysaccharides, bibenzyls (1-22), phenanthrenes (23-28), phenylpropanoids (29-44), flavonoids (45-103), alkaloids (104-108), acids (109-116), and others (117-126). Among them, polysaccharides, bibenzyls, and flavonoids are considered the main bioactive compounds responsible for various pharmacological properties and therapeutic efficacy of $D$. officinale. All compounds identified in D. officinale are summarized and shown in Table 2, and the corresponding structures are shown in Figures 2-8.

\section{Polysaccharides}

Polysaccharides are the main medicinal components of $D$. officinale, with a wide range of medicinal properties. A large number of polysaccharides have been isolated from $D$. officinale, including DWDOP1, DWDOP2, DWDOP3, FWDOP1, FWDOP2, FWDOP3 (Yu et al., 2018), DOP-50, DOP-60, DOP-70 (Xing et al., 2018), DO (Ma et al., 2018), DOPA-1 (Wei et al., 2018), DOP1-DES, DOP2-DES (Liang J et al., 2018), LDOP-1 (Yang et al., 2020), UDP-1, FLP-1, and FDP-1 (Liang K. $L$ et al., 2018), which are identified by various analytical technologies, such as high performance liquid chromatography (HPLC), high performance gel permeation chromatography (HPAEC), gas chromatography-mass spectrometry (GC-MS), and gel permeation chromatography (GPC). The molecular weights of $D$. officinale polysaccharides range from 30 to 1,415 kDa (Liang J et al., 2018; Ma et al., 2018;
Wei et al., 2018; Yu et al., 2018). It has been demonstrated that $D$. officinale polysaccharides are composed of glucose, mannose, galactose, xylose, arabinose, ribose and rhamnose (Tian et al., 2019). Among them, glucomannan is considered to be the main component of $D$. officinale polysaccharides with 1,4- $\beta$-D-Man $p$ and $1,4-\beta-\mathrm{D}-\mathrm{Gl} c p$, comprising acetyl groups in varying degrees and positions with or without branches (Liang et al., 2019). It should be mentioned that a lot of factors may impact the biological activity of polysaccharides, including molecular structure, main chain composition, molecular branching degree, the configuration of the main chain, and chemical modification (Yue et al., 2017; Huang et al., 2020). Importantly, according to the literature, polysaccharides have exhibited various therapeutic potentials, including cardioprotective (Zhang et al., 2017a; Su et al., 2021), antitumor (Wei et al., 2018; Zhao et al., 2019), gastrointestinal protective (Ke et al., 2020; Zhang et al., 2020), immunomodulatory (Huang et al., 2018), anti-aging (Liang et al., 2017; Wei et al., 2017), and pulmonary protective effects (Chen et al., 2020).

\section{Bibenzyls}

Bibenzyl components in $D$. officinale have attracted a lot of attention due to their promising anti-tumor properties $(\mathrm{He}$ et al., 2020). To date, 19 bibenzyls have been isolated, which were identified predominantly from the stems and leaves of $D$. officinale. The typical parent nucleus structure of bibenzyls presented in the stems of $D$. officinale is two benzene rings, which can be replaced by different substituents. Some bibenzyls $(4,5$, and 7$)$ were found to have significant anti-tumor activity (Tian et al., 2019; Zhao et al., 2020), which attracted further research and development. The chemical structures of these bibenzyls are shown in Figure 2.

\section{Phenanthrenes}

The phenanthrenes are abundantly found in the stems of $D$. officinale, including ephemeranthol A (23), erianthridin (24), orchinol (25), 2, 4, 7-trihydroxy-9, 10-dihydrophenanthrene (26), confusarin (27), and 2,7-dihydroxy-3,4dimethoxyphenanthrene (28). Notably, orchinol (25) possesses anti-tumor activity, which can potentially be used to develop new anti-tumor drugs (Zhao et al., 2018a). The chemical structures of these phenanthrenes are shown in Figure 3. 
<smiles>[R]Cc1cc(CCc2cc([R3])c([R9])c([R])c2)cc([R])c1[R]</smiles>

$1 \mathrm{R}_{1}=\mathrm{R}_{3}=\mathrm{OMe}, \mathrm{R}_{2}=\mathrm{R}_{5}=\mathrm{OH}, \mathrm{R}_{4}=\mathrm{R}_{6}=\mathrm{H}$ $2 \mathbf{R}_{\mathbf{1}}=\mathbf{R}_{\mathbf{5}}=\mathrm{OH}, \mathbf{R} 2=\mathbf{R} 4=\mathrm{R} \mathbf{6}=\mathrm{H}, \mathbf{R}_{\mathbf{3}}=\mathrm{OMe}$ $3 \mathbf{R}_{\mathbf{1}}=\mathbf{R}_{\mathbf{2}}=\mathrm{OH}, \mathbf{R}_{\mathbf{3}}=\mathrm{R}_{\mathbf{5}}=\mathrm{OCH}_{3}, \mathbf{R}_{\mathbf{4}}=\mathbf{R}_{\mathbf{6}}=\mathrm{H}$ $4 \mathrm{R}_{1}=\mathrm{R}_{5}=\mathrm{OH}, \mathrm{R}_{2}=\mathrm{R}_{6}=\mathrm{H}, \mathrm{R}_{3}=\mathrm{R}_{4}=\mathrm{OMe}$ $5 \mathbf{R}_{1}=\mathbf{R}_{3}=\mathbf{R}_{4}=\mathrm{OMe}, \mathrm{R}_{2}=\mathbf{R}_{5}=\mathrm{OH}, \mathrm{R}_{6}=\mathrm{H}$ $6 \mathrm{R}_{\mathbf{1}}=\mathrm{R}_{3}=\mathrm{R}_{5}=\mathrm{OH}, \mathrm{R}_{6}=\mathrm{OMe}, \mathrm{R}_{2}=\mathrm{R}_{4}=\mathrm{H}$ $7 \mathbf{R}_{\mathbf{1}}=\mathbf{R}_{\mathbf{2}}=\mathbf{R}_{3}=\mathbf{R}_{5}=\mathrm{OMe}, \mathbf{R}_{6}=\mathrm{OH}, \mathbf{R}_{\mathbf{4}}=\mathrm{H}$ $8 \mathbf{R}_{\mathbf{1}}=\mathrm{R}_{3}=\mathrm{H}, \mathrm{R}_{2}=\mathrm{R}_{4}=\mathrm{R}_{5}=\mathrm{OH}, \mathrm{R}_{6}=\mathrm{OMe}$ $9 \mathbf{R}_{1}=\mathrm{R}_{3}=\mathbf{R}_{5}=\mathrm{H}, \mathrm{R}_{2}=\mathrm{R}_{6}=\mathrm{OMe}, \mathbf{R}_{4}=\mathrm{OH}$ $10 R_{1}=R_{3}=H, R_{2}=R_{4}=R_{5}=R_{6}=O M e$ $11 R_{1}=R_{2}=R_{3}=R_{6}=O M e, R_{5}=O H, R_{4}=H$ $12 R_{1}=R_{3}=R_{5}=H, R_{2}=R_{4}=R_{6}=O H$<smiles>COc1ccc(CCc2cc(OC)c3c(c2)OC(CO)[C@@H](c2ccc(O)c(OC)c2)O3)cc1</smiles>

17<smiles>COc1ccc(CC(O)c2cc(O)c(O)c(OC)c2)cc1</smiles>

19<smiles>COc1cc(C2Oc3cc4ccc5cc(O)ccc5c4c(OC)c3O[C@H]2CO)cc(OC)c1O</smiles><smiles>COc1ccc(CCc2ccc3c(c2)OC(c2cc([N+](=O)[O-])c(O)c([N+](=O)[O-])c2)C(CO)O3)cc1</smiles><smiles>CCc1cc(OC)c2c(c1)O[C@H](COC(=O)CCc1ccc(O)cc1)[C@@H](c1cc(OC)c(O)c(OC)c1)O2</smiles>

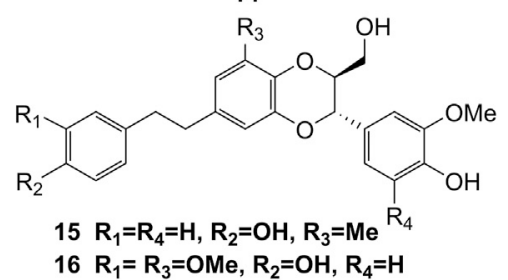<smiles>COc1cc(CCc2cc(O)cc3c2C[C@H](O)[C@@H](c2ccc(O)c(OC)c2)O3)ccc1O</smiles><smiles>COc1cc(C2Oc3cc(CCc4ccc(O)cc4)cc(OC)c3OC2CO)ccc1O</smiles>

20<smiles>COc1cc(C2Oc3cc4c(c(OC)c3O[C@H]2CO)-c2ccc(O)cc2CC4)cc(OC)c1O</smiles>

\section{Phenylpropanoids}

Phenylpropanoid compounds refer to natural organic compounds with one or more $\mathrm{C}_{6}-\mathrm{C}_{3}$ units in the basic parent nucleus, mainly including simple phenylpropanoids, coumarins, and lignans. To date, 16 phenylpropanoids (29-44) have been identified in $D$. officinale, including simple phenylpropanoids (29-35), coumarin (36), and lignans (37-44). The chemical structures of these phenylpropanoids are presented in Figure 4.

\section{Flavonoids}

It has been reported that flavonoids belong to a large group of secondary metabolites in D. officinale, which possess anti-tumor activity (Xing et al., 2018). Most flavonoids isolated and identified from the roots, stems, leaves, and flowers of $D$. officinale are $\mathrm{C}$-glycosides, while the rest of flavonoids are $\mathrm{O}$-glycosides. It is well known that the foundational skeletons of flavonoids are apigenin, vitexin, quercetin, and kaempferol. Nowadays, mass spectrometry technologies coupled with liquid chromatography, such (HPLC-ESI-MS) (Ye et al., 2017), ultra-high-performance liquid chromatography (UPLC-ESI-MS/MS) (Zhou et al., 2018), and UPLC-quadrupole time of flight mass spectrometry (UPLCQTOF-MS) (Yu et al., 2018), have been widely implemented for the identification and quantification of these flavonoid compounds. Interestingly, it is generally believed that glucoside derivatives (anthocyanins) delphinidin 3,5$O$-diglucoside and cyanidin 3-O-glucoside are responsible for 


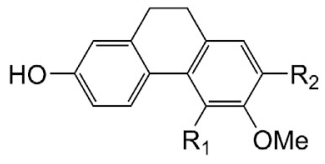

$23 \mathrm{R}_{1}=\mathrm{OH}, \mathrm{R}_{2}=\mathrm{OMe}$ $24 \mathrm{R}_{1}=\mathrm{OMe}, \mathrm{R}_{2}=\mathrm{OH}$

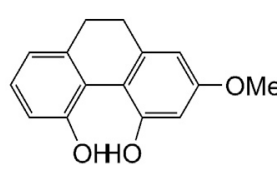

25

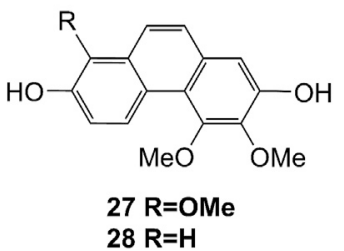

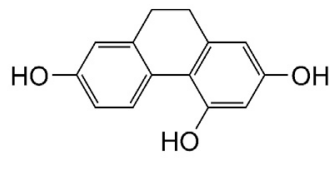

26

FIGURE 3 | Structures of phenanthrenes (23-28) isolated from D. officinale.

the red color stems of D. officinale (Yu et al., 2018). In addition, the transcriptome and component metabolism analyses have become the typical approaches to investigate flavonoid biosynthesis mechanisms in D. officinale (Lei et al., 2018). The chemical structures of these flavonoids are shown in Figures 5-7.

\section{Alkaloids}

Alkaloids are a class of nitrogenous organic compounds possessing various biological activities. They are also active constituents of Dendrobium plants. It is worth noting that the regulation of genes related to alkaloid biosynthetic pathways through comparative transcriptomic analysis has gradually become a research interest (Jiao et al., 2018). The chemical structures of these alkaloids are shown in Figure 8.

\section{Organic Acids}

Organic acids are a kind of acid organic compounds containing a carboxyl group. Eight types of organic acids have been identified in D. officinale. The chemical structures of these organic acids are displayed in Figure 9.

\section{Other Compounds}

Some other types of compounds have also been isolated from the stems and leaves of D. officinale, including flifimdioside A (117), flickinflimoside B (118) (Chen et al., 2018), loliolide (119), 1glycerol linolenate (120), densiflorol A (121), 2-butoxyethyl linolenate (122), catechol (123) (Ren et al., 2020a), octadecadienoic acid-2,3-dihydroxypropyl ester (124) stigmast5-en-3ß-ol-7-one (125) (Zhu et al., 2020), and dendrofindlaphenol B (126) (Liu et al., 2018). The chemical structures of these compounds are shown in Figure $\mathbf{1 0 .}$

\section{PHARMACOLOGY}

D. officinale has been found to possess multiple biological functions, including cardioprotective (Zhang et al., 2017a; Su et al., 2021), anti-tumor (Guo et al., 2019), gastrointestinal protective (Liu et al., 2020), anti-diabetes (Zeng et al., 2020), immunomodulatory (Huang et al., 2018), anti-aging (Liang et al., 2017), and anti-osteoporosis (Wang et al., 2018) effects. Among them, modern pharmacological studies of $D$. officinale majorly focus on its cardioprotective, anti-tumor, gastrointestinal protective, and hypoglycemic effects. The biological activities of D. officinale and corresponding mechanisms are shown in Figure 11.

\section{Cardioprotective Activity}

Cardiovascular diseases are the major causes of mortality globally, and the main cause of more than 10 million people death. Among cardiovascular diseases risk factors, cardiomyopathy and high blood pressure are the most common ones. Oral administration of $D$. officinale fine powders at the doses of $0.09,0.18$, and a very high dose of $1.1 \mathrm{~g} / \mathrm{kg}$ for 30 days protected isoproterenol (ISO)induced cardiac hypertrophy, indicated by the decreased myocardial collagen synthesis, increased myocardial fibrosis and ventricular remodeling, and significantly reduced levels of atrial natriuretic peptide (ANP), brain natriuretic peptide (BNP), and cardiac troponin I (cTN-I) in plasma relative to the model group (ISO $=5 \mathrm{mg} / \mathrm{kg}$ ) (Xiao et al., 2018). In addition, it was well known that diabetic cardiomyopathy was a typical cardiovascular complication mediated via hyperglycemia. One study indicated that $D$. officinale water-soluble extracts prevented diabetic cardiomyopathy and might be a candidate for therapeutic use (Zhang et al., 2016). D. officinale water extracts (75, 150, and $300 \mathrm{mg} / \mathrm{kg}$ ) intragastrically once daily for 2 weeks could protect left anterior descending coronary artery (LAD)-induced myocardial ischemia through decreasing creatine kinase (CK)$\mathrm{MB}$, lactate dehydrogenase (LDH), malondialdehyde (MDA), and increasing superoxide dismutase (SOD) and Meis 1 levels (Dou et al., 2016). Treatment with D. officinale stems polysaccharide DOP-GY at the doses of $6.25,12.5$, and $25 \mu \mathrm{g} /$ $\mathrm{ml}$ exhibited protective effects on hydrogen peroxide $\left(\mathrm{H}_{2} \mathrm{O}_{2}\right)$ induced H9c2 cardiomyocyte apoptosis via phosphatidylinositol/ protein kinase $\mathrm{B}(\mathrm{PI} 3 \mathrm{~K}) / \mathrm{Akt}$ and mitogen-activited protein kinase (MAPK) signaling pathways, as demonstrated by the decreased levels of $\mathrm{LDH}$, lipid peroxidation damage (LPD), reactive oxygen species (ROS), and pro-apoptosis protein (Zhang et al., 2017a). 
<smiles>O=C(O)/C=C/c1ccc(O)c(Br)c1</smiles>

$29 \mathbf{R}_{1}=\mathrm{OH}, \mathbf{R}_{2}=\beta$-D-Glc $30 \mathrm{R}_{1}=\mathrm{H}, \mathrm{R}_{2}=\beta$-D-Glc<smiles>CCOC(=O)CCc1ccc(O)cc1</smiles>

31<smiles>COc1c(O)cccc1C(=O)CCO</smiles>

32<smiles>COc1cc(CCCOC(=O)CCc2ccc(O)cc2)ccc1O</smiles>

33

34

35

36<smiles>COc1cc(C2OCC3C(c4cc(OC)c(O)c(OC)c4)OCC23)cc(OC)c1O</smiles><smiles>COc1cc2ccc(=O)oc2cc1OC</smiles>

37

38<smiles>COc1ccc([C@H]2CO[C@H]3[C@H](c4ccc(OC)c(OC)c4)OC[C@@H]23)cc1OC</smiles>

39

40<smiles>COc1cc(C2CC3C(CO2)COC3c2cc(OC)c(OC)c(OC)c2)cc(OC)c1O</smiles>

42

43

44

FIGURE 4 | Structures of phenylpropanoids (29-44) isolated from $D$. officinale.

Another study demonstrated that $D$. officinale polysaccharides could decrease malondialdehyde levels, increase SOD activities, and inhibit the generation of intracellular ROS in H9c2 cardiomyocytes (Zhao et al., 2017). Besides, Yue et al. (2017) obtained a novel homogeneous heteroxylan from alkali-extracted D. officinale crude polysaccharide (S32), which possessed significant anti-angiogenic effects $(\mathrm{S} 32,13.51 \mu \mathrm{M})$ on human microvascular endothelial cells (HMEC-1) by inhibiting their migration and disruption of tube formation in a dosedependent manner, compared with a vehicle group (Yue et al., 2017). However, some of these experimental doses were too high and there was a lack of positive controls.

It has been suggested that $D$. officinale has cardioprotective activity by treating hypertension. It was reported that blood pressure was significantly reduced after treating with $D$. officinale
(10 g/d) (Wu et al., 2018b). The treatment of D. officinale ultrafine powder (DOFP) at very high doses of 200 and $400 \mathrm{mg} / \mathrm{kg}$ for 20 weeks exhibited anti-hypertensive activity on overeating greasy-induced metabolic hypertension in rats by inhibiting the activation of lipopolysaccharide/toll-like receptor 4 (LPS/TLR4) signal pathway, as demonstrated by the decreased levels of total cholesterol (TC), triglyceride (TG), low-density lipoprotein cholesterol (LDL-c), LPS, C-reactive protein (CRP), interleukin 6 (IL-6), TLR4, myeloid differentiation factor (MyD88), IL-1 $\beta$, and tumor necrosis factor alpha (TNF- $\alpha$ ) and the increased levels of high-density lipoprotein cholesterol (HDL-c) and nitric oxide (NO) relative to valsartan $(8 \mathrm{mg} / \mathrm{kg}$ )-treated positive control (Su et al., 2021). Moreover, Yan et al. (2019a) reported that the effective component of alcohol extract of $D$. officinale in the treatment 
<smiles>Oc1ccc(C2=CC(O)c3c(O)cc(O)cc3O2)cc1</smiles>

45<smiles>O=C1CC(O)(c2ccc(O)cc2)Oc2cc(O)cc(O)c21</smiles>

48<smiles>COc1cc(C2CC(=O)c3c(O)cc(O)cc3O2)ccc1O</smiles>

51<smiles>COc1cc(-c2oc3cc(O)cc(O)c3c(=O)c2O)ccc1O</smiles>

54<smiles>O=C(OCc1ccccc1)OC1=CC2OC(c3ccc(O)cc3)=CC(=O)C2C(O)=C1</smiles>

57<smiles>[R9]C1CC(O)C2C(=O)C=C(c3ccc(O)cc3)OC2=CC1O</smiles>

46

47 R=Glc-Ara<smiles>O=C(CCc1ccc(O)cc1)c1c(O)cc(O)cc1O</smiles>

49<smiles>O=c1c(O)c(-c2ccc(O)c(O)c2)oc2cc(O)cc(O)c12</smiles>

52<smiles>O=c1c(O)c(-c2ccc(O)c(O)c2)oc2cc(O)cc(O)c12</smiles>

55<smiles>[R20]Oc1cc2c(O[R2])cc(O)cc2[o+]c1-c1ccc(O)cc1</smiles>

$58 \mathrm{R}_{1}=\mathrm{Glc}, \mathrm{R}_{2}=\mathrm{Glc}$ $59 \mathrm{R}_{1}=$ Rut, $\mathrm{R}_{2}=\mathrm{H}$<smiles>O=C1c2c(O)cc(O)cc2OC(c2ccc(O)c(O)c2)C1O</smiles>

53<smiles>COc1cc(C2OC3CC(O)CC(O)C3C(=O)C(O)C2O)ccc1O</smiles>

56<smiles>COc1cc2c(O)cc(O)cc2[o+]c1-c1cc(OC)c(O)c(OC)c1</smiles>

60

FIGURE 5 | Structures of flavonoids (45-60) isolated from D. officinale.

of metabolic hypertension was apigenin flavonoid glycosides (Yan et al., 2019a). In contrast, more investigations are still needed to reveal the underlying mechanism of the antihypertensive effect of apigenin flavonoid glycosides. The results showed that treatment with $D$. officinale flowers at a very high dose of $3.1 \mathrm{~g} / \mathrm{kg}$ for 6 weeks could significantly improve vascular diastolic function by reducing systolic blood pressure and mean arterial pressure in high glucose and fat compound alcohol-induced hypertensive rats, inhibiting the thickening of thoracic aorta and the loss of endothelial cells, reducing plasma content of endothelin 1 (ET-1) and thromboxane B2 (TXB2), and increasing the content of prostacycline (PGI2) and NO, compared with model control group and valsartan $(5.7 \mathrm{mg} / \mathrm{kg})$ positive control group (Liang K. L et al., 2018). Treating with D. officinale ultrafine powder DOFP could improve the intestinal flora and increase the production, transportation, and utilization of short-chain fatty acid (SCFA), activate the intestinal-vascular axis SCFA-GPCR43/41 pathway, increase vascular endothelial function, and finally decrease the blood pressure in alcohol, and high sugar and fat diets (ACHSFD)-induced metabolic hypertension model rats (Li et al., 2021). These results suggested that $D$. officinale may have a potential clinical application in the treatment of hypertension. In this study, however, the optimal dose, constituents, and side effects of $D$. officinale are not assessed. Moreover, further detailed clinical trials should be employed to assess the value of $D$. officinale as a drug for the treatment of hypertension. In addition, this evidence is still tenuous; no double-blind trials involving $D$. officinale have been performed, and more evidence from randomized controlled trials is required to elucidate other mechanisms that may be responsible for anti-hypertension effects.

Although D. officinale possesses a potential therapeutic effect on cardiovascular diseases, especially cardiomyopathy and hypertension (Figure 12), more in-depth investigations on its 
<smiles>[R]c1c(O)c([R])c2oc(-c3ccc(O)cc3)cc(=O)c2c1O</smiles>

$61 R_{1}=X y l, R_{2}=G l c$

$62 R_{1}=G\left|c, R_{2}=G\right| c$

$63 R_{1}=G \mid c, R_{2}=X l y$

$64 R_{1}=G l c, R_{2}=R h a$

$65 R_{1}=$ Ara, $R_{2}=G l c$

$66 R_{1}=G \mid c, R_{2}=$ Ara

$67 \mathrm{R}_{1}=\mathrm{H}, \mathrm{R}_{2}=\mathrm{Glc}$-GIc

$68 \mathrm{R}_{1}=\mathrm{Glc}, \mathrm{R}_{2}=\mathrm{H}$

$69 \mathrm{R}_{1}=X 1 y, \mathrm{R}_{2}=$ Ara

$70 R_{1}=$ Ara, $R_{2}=$ Ara

$71 R_{1}=$ Rha, $R_{2}=$ Glc

$72 R_{1}=$ Ara, $R_{2}=X l y$

$73 \mathrm{R}_{1}=$ Ara-GIc, $\mathrm{R}_{2}=\mathrm{H}$

$74 \mathrm{R}_{\mathbf{1}}=\mathrm{Glc}, \mathbf{R}_{\mathbf{2}}=b$-L-Ara

$75 R_{1}=H, R_{2}=$ Glc $-(1 \rightarrow 2)-G l c$

$76 \mathrm{R}_{1}=\mathrm{Glc}, \mathrm{R}_{2}=\mathrm{Glc}$

$77 \mathbf{R}_{1}=\mathrm{H}, \mathbf{R}_{2}=\beta$-D-Glc-(1 $\left.\rightarrow 4\right)-\beta$-D-Glc

$78 \mathbf{R}_{1}=\beta$-D-Xly, $\mathbf{R}_{2}=\alpha$-L-Ara

$79 \mathbf{R}_{1}=\alpha$-L-Ara, $\mathbf{R}_{2}=\beta$-D-Xyl

$80 \mathbf{R}_{\mathbf{1}}=\alpha$-L-Rha, $\mathbf{R}_{2}=\beta$-D-Xyl

$81 \mathbf{R}_{1}=$ Ara- $(1 \rightarrow 2)-\beta$-D-Glc, $\mathbf{R}_{2}=\mathrm{H}$

$82 \mathbf{R}_{\mathbf{1}}=\mathrm{H}, \mathbf{R}_{\mathbf{2}}=\mathrm{Glc}-(1 \rightarrow 2)-\alpha$-L-Ara

83 R1=Glc- $(1 \rightarrow 2)-\alpha$-L-Ara, R2=H

$84 \mathbf{R}_{1}=\beta$-D-Xly, $\mathbf{R}_{2}=\beta$-D-Glc

$85 \mathbf{R}_{1}=\beta$-D-Glc, $\mathbf{R}_{2}=\beta$-D-Xly<smiles>COc1cc(/C=C/C(=O)OCC2OC(Oc3cc4c(OC5O[C@H](CO)[C@@H](O)[C@H](O)[C@H]5O)cc(O)cc4[o+]c3-c3ccc(O)c(O)c3)[C@H](O)[C@H](O)[C@@H]2O)cc(OC)c1O</smiles><smiles>[R]c1ccc(-c2oc3cc(O)cc(O)c3c(=O)c2[R])cc1[R]</smiles>

$86 \mathrm{R}_{1}=\mathrm{OH}, \mathbf{R}_{2}=\mathrm{OH}, \mathbf{R}_{\mathbf{3}}=\mathrm{Glc}$

$87 \mathrm{R}_{1}=\mathrm{OH}, \mathrm{R}_{2}=\mathrm{H}, \mathrm{R}_{3}=$ Aha- $(1 \rightarrow 6)$-Glc

$88 \mathrm{R}_{1}=\mathrm{OH}, \mathrm{R}_{2}=\mathrm{H}, \mathrm{R}_{3}=\mathrm{Glc}$

$89 \mathrm{R}_{1}=\mathrm{OH}, \mathrm{R}_{2}=\mathrm{OMe}, \mathrm{R}_{3}=\mathrm{Glc}$

$90 \mathrm{R}_{1}=\mathrm{OMe}, \mathrm{R}_{2}=\mathrm{OH}, \mathrm{R}_{3}=\mathrm{Glc}$<smiles>[R20]Oc1c([R20])c(O)c(O)c(C(=O)CCc2ccc(O)cc2)c1O</smiles>

$91 R_{1}=G \mid c, R_{2}=H$

$92 R_{1}=G l c, R_{2}=G l c$<smiles>[R]Oc1cc2c(O)cc(O)cc2[o+]c1-c1ccc(O)c(OCCCCCCCCCC)c1</smiles>

FIGURE 6 | Structures of flavonoids (61-97) isolated from $D$. officinale.

effective monomer compounds, molecular mechanism, and clinical trials are warranted to identify effective cardioprotective agents with minimized side effects.

\section{Anti-Tumor Activity}

As a type of traditional medicine and ordinary food, D. officinale has benefits on human health supported by its effectiveness in the prevention and treatment of cancer diseases (Guo et al., 2019). Several studies have reported all crude extracts, polysaccharides, and other pure compounds isolated from $D$. officinale exhibited anti-tumor activities (Wei et al., 2018; Guo et al., 2019; Zhao et al., 2020).

Administration of $D$. officinale methanol extracts at a dose of $0.25,0.5$, and $1 \mathrm{mg} / \mathrm{ml}$ could inhibit the growth of SMMC-7721, BEL-7404 cells, and primary liver cancer cells, and promote their apoptosis via activating mitochondria apoptosis pathway and suppressing the Wnt/ $\beta$-catenin pathway (Guo et al., 2019). Similarly, another study demonstrated that $D$. officinale 


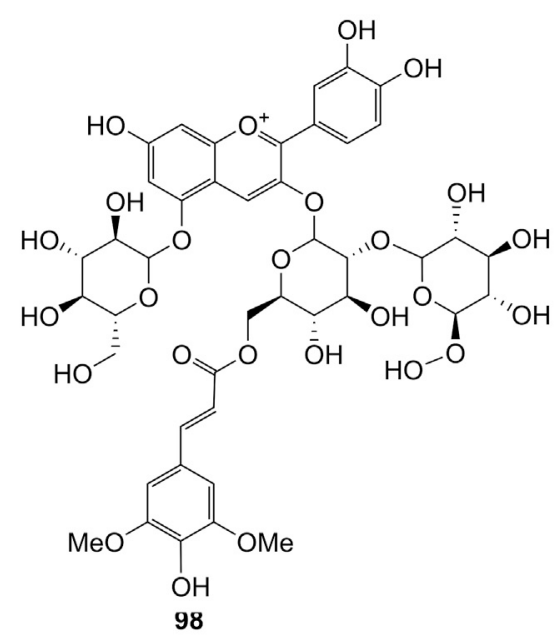<smiles>COc1cc(/C=C/C(=O)OCC2OC(Oc3cc4cc5c(O)cc(O)cc5[o+]c4cc3O)[C@H](O)[C@H](O)[C@H]2O)ccc1O</smiles>

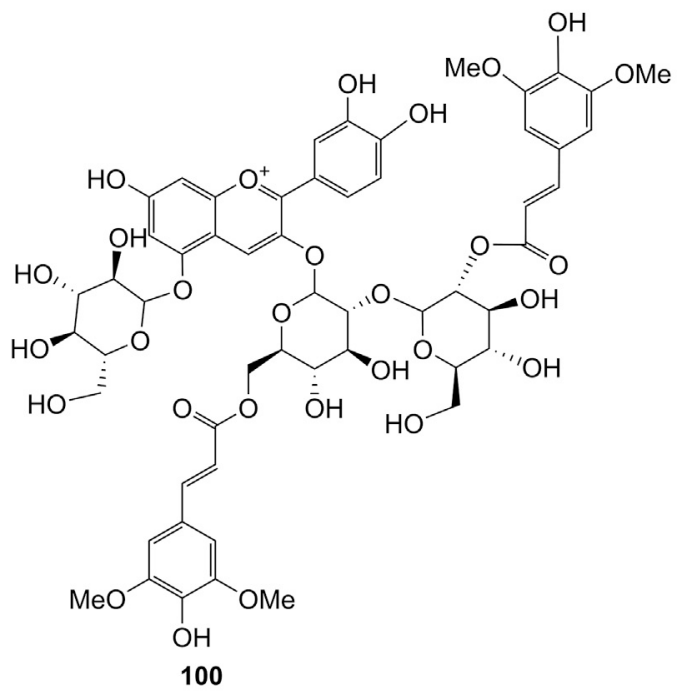<smiles>Cc1cc(/C=C/C(=O)OCC2OC(Oc3cc4c(O)cc(O)cc4[o+]c3-c3ccc(O)c(O)c3)C(O)C(O)C2O)cc([N+](=O)[O-])c1O</smiles>

101<smiles>O=C([O-])Oc1cc(O)cc2c(O)cc(O)cc12</smiles><smiles></smiles>

103

FIGURE 7 | Structures of flavonoids (98-103) isolated from $D$. officinale.

polysaccharide (DOPA-1) induced HepG-2 cell apoptosis by influencing mitochondrial function, ROS production, and apoptosis-related protein expression (Wei et al., 2018). Importantly, a rat study also confirmed the anti-tumor effects of $D$. officinale in vivo. The 2-weeks administration of $D$. officinale polysaccharide DOP at very doses of $2.4,4.8$, and $9.6 \mathrm{~g} / \mathrm{kg}$ suppressed 1-methyl-2-nitro-1-nitrosoguanidine-(MNNG)induced $(150 \mu \mathrm{g} / \mathrm{ml})$ precancerous lesions of gastric cancer in rats via modulating $\mathrm{Wnt} / \beta$-catenin pathway and altering endogenous serum metabolites (Zhao et al., 2019). In addition to crude extracts and polysaccharides, it is more evident that gigantol (4), moscatilin (5), erianin (7), orchinol (25), and isoviolanthin (71) isolated from D. officinale are also responsible for the anticancer activity of $D$. officinale (Xing et al., 2018; Liu et al., 2019; Lee et al., 2020; Zhao et al., 2020). Gigantol (4) was found to repress invasiveness and growth of SW780, 5,637, and T24 human bladder cancer cells by inhibiting the Wnt/epithelial-mesenchymal transition (EMT) signaling (Guo et al., 2019). Likewise, moscatilin (5) was demonstrated to induce apoptosis in $\mathrm{FaDu}$ human head and neck squamous carcinoma cells (HNSCC) via c-Jun N-terminal kinase (JNK) signaling pathway (Lee et al., 2020). The anti-tumor function of erianin (7) was investigated by two independent studies. The results suggest that erianin (7) induced cell apoptosis through the 

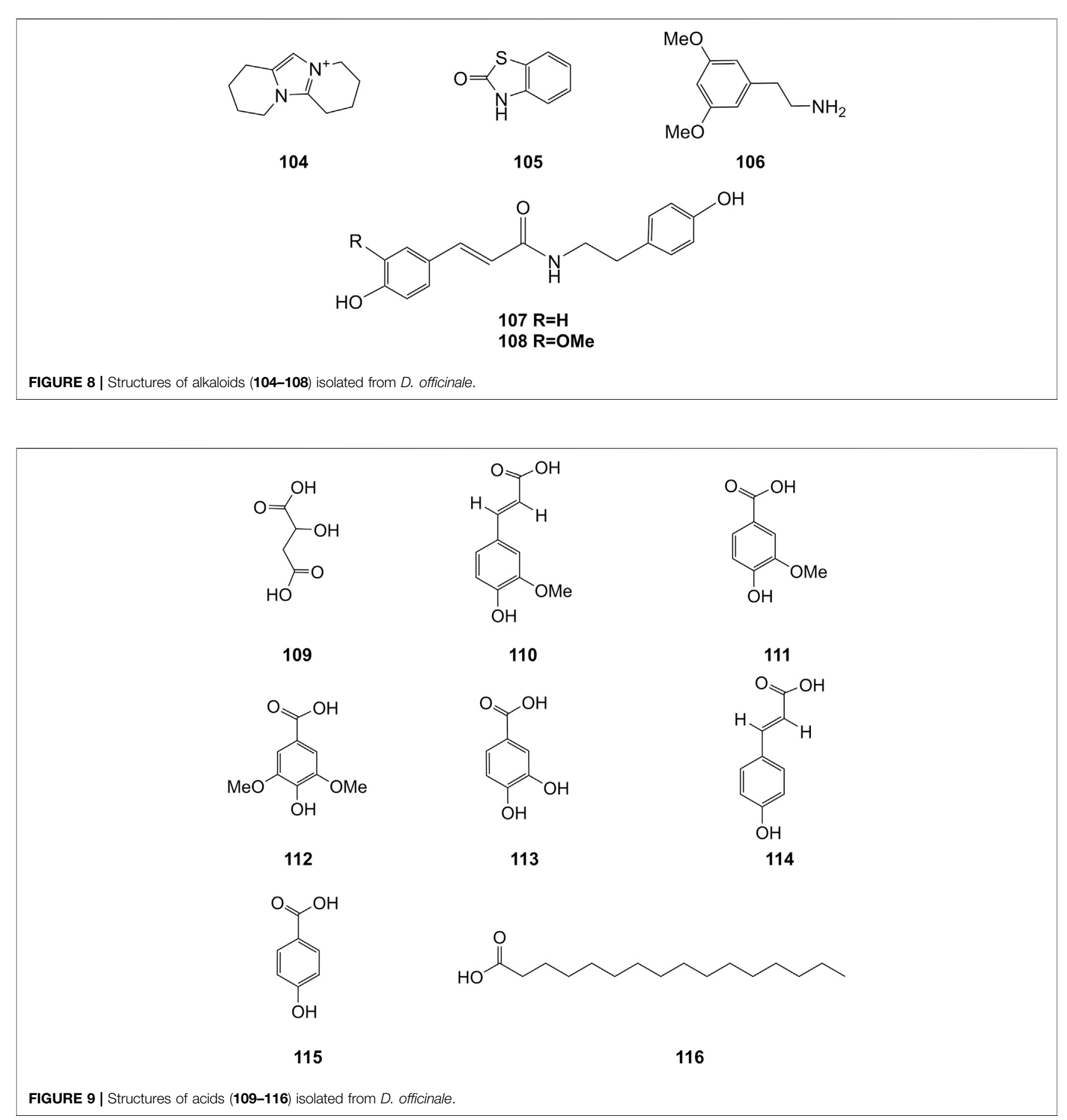

ERK pathway in nasopharyngeal carcinoma (NPC) (Liu et al., 2019) while suppressing the growth of bladder cancer cells EJ and T24 through JNK pathways with the $\mathrm{IC}_{50}$ values of 65.04 and $45.9 \mathrm{nM}$, respectively (Zhu et al., 2019). Moreover, it was demonstrated that orchinol (25) exhibited strong cytotoxic activity in HI-60 and THP-1 cells with the $\mathrm{IC}_{50}$ values of 11.96 and $8.92 \mu \mathrm{M}$, respectively (Lee et al., 2020). Additionally, isoviolanthin (71) was revealed to suppress transforming growth factor (TGF)- $\beta 1$-induced EMT through the regulation of TGF$\beta /$ Smad and PI3K/Akt/mTOR signaling pathways in HepG2 and Bel-7402 hepatocellular carcinoma (HCC) cells (Xing et al., 2018). However, the dose of D. officinale polysaccharide DOP was too high in the treatment of gastric cancer, attention should be paid to the possible side-effects in clinical applications.

Overall, the anti-tumor mechanisms of $D$. officinale are mainly attributed to promoting tumor cell apoptosis, inhibiting tumor 


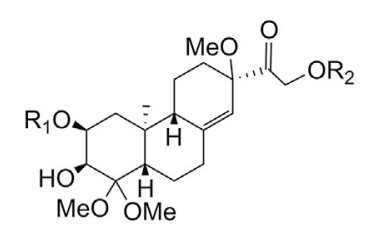

$117 \mathrm{R}_{1}=\mathrm{Me}, \mathrm{R}_{\mathbf{2}}=\mathrm{Glc}$ $118 \mathrm{R}_{1}=\mathrm{H}, \mathrm{R}_{2}=\mathrm{Glc}$<smiles>COc1cc(O)cc(CCc2ccc3c(c2)OCO3)c1</smiles>

121

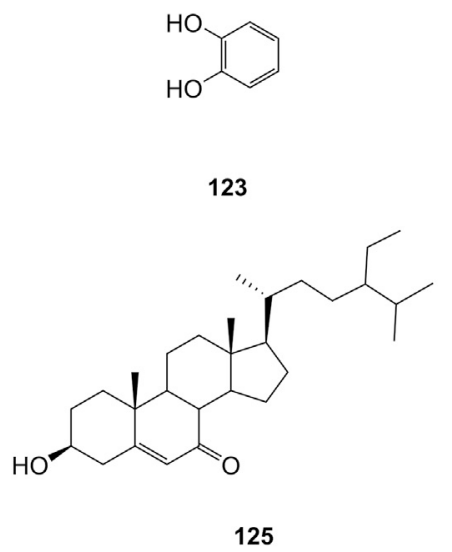<smiles>CC/C=C\C/C=C\C/C=C\CCCCCCCC(=O)OCC(O)CO</smiles>

119<smiles>C=CC(=O)OCCOCCCC(CCC/C=C/C/C=C/C/C=C/CCCCC)C(=O)O</smiles>

122<smiles>CCCCCCCC/C=C\CCCCCCCC(=O)OCC(O)CO</smiles>

124<smiles>COc1ccc(CCc2cc(OC)c3c(c2)OC(c2ccc(O)c(OC)c2)[C@@H](CO)C3)cc1</smiles>

126

FIGURE $10 \mid$ Structures of other compounds (117-126) isolated from D. officinale.

cell proliferation, repressing tumor cell migration and invasion, and improving body immunity (Figure 13). The studies described above suggest that the compounds identified in $D$. officinale demonstrate significant inhibitory effects on different types of tumor cells, such as SMMC-7721, BEL-7404, HepG-2, SW780, and HCC cell lines. Further investigations may explore the structural modification and the structure-activity relationship (SAR) studies for these bioactive compounds of $D$. officinale, thereby facilitating the further discovery and development of new anti-tumor candidates, along with the characterization of the key regulatory genes, metabolic pathways, and heterologous biosynthesis pathways of active ingredients from $D$. officinale. The currently published studies on the anti-tumor effects of the compounds from $D$. officinale are mainly focused on in vitro and in vivo experiments, while clinical studies have yet to be conducted and the exact molecular mechanisms remain elusive.

\section{Gastrointestinal Protective Effect}

D. officinale is traditionally used to nourish "Yin" and thicken stomach. D. officinale extracts have thus been frequently applied to treat gastrointestinal diseases as a traditional Chinese medicine. It was reported that polyphenols from fermentation liquid of $D$. officinale improved intestinal health via the regulation of intestinal microbiota and their metabolites, thereby relieving oxazolone-induced intestinal inflammation in Zebrafish (Gong et al., 2020). Moreover, D. officinale is often used in combination with other traditional Chinese medicines to achieve its better therapeutic effects. It was found that the mixture of $D$. officinale and American ginseng at a dose of $(0.32 \times$ the dog's weight $\times 6 \mathrm{~g}) /$ $12 \mathrm{~kg}$ ) could function as a prebiotic agent to enhance SCFAproducing genera and reverse gut dysbiosis (Liu et al., 2020). Likewise, the combination of $D$. officinale and other Chinese herbal medicine, such as Acanthopanax senticosus, Panaxnotoginseng, Didymocarpus hancei and Valeriana officinalis can also alleviate gastric mucosal injury (Guo, 2020b).

The 14-days treatment of $D$. officinale glucomannans at $0.16 \mathrm{~g} / \mathrm{kg}$ produced more SCFAs (mainly acetate and butyrate) in cecum and colon (Shi et al., 2020). It should be noted that polysaccharides LDOP-1 isolated from $D$. officinale could protect ethanol-induced gastric mucosal injury in vitro $(250,125$, and $62.5 \mathrm{mg} / \mathrm{ml}$ for $2 \mathrm{~h}$ ) and in vivo (100 and a very high dose of $400 \mathrm{mg} / \mathrm{kg}$ for 30 days) by regulating AMP-activated protein 


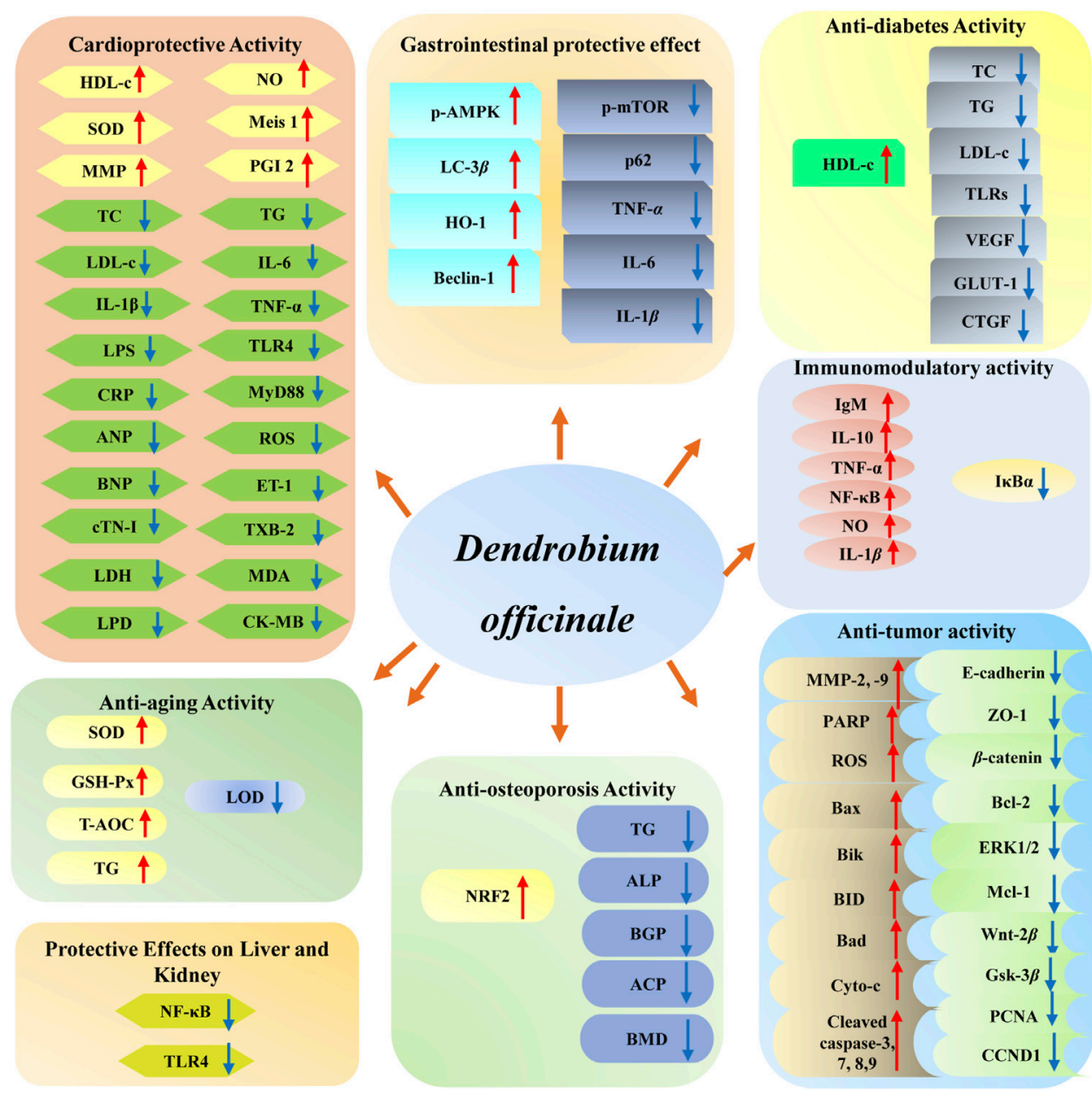

FIGURE 11 | The bioactivities of main compounds isolated from $D$. officinale and their underlying mechanisms.

kinase $(\mathrm{AMPK}) / \mathrm{mTOR}$ signaling pathway demonstrated by the increased levels of $\mathrm{p}$-AMPK, light chain $3 \beta$ (LC-3 $\beta$ ), heme oxygenase-1 (HO-1) and Beclin-1, the decreased levels of p-mTOR and p62, and the reversed levels of caspase3, Bax, and Bcl-2 detected both in vitro and in vivo (Ke et al., 2020). Furthermore, it was suggested that $D$. officinale polysaccharide $(200 \mathrm{mg} / \mathrm{kg} / \mathrm{d})$ exhibited protective effects against DSS-induced colitis by inhibiting pro-inflammatory cytokines TNF- $\alpha$, IL-6, and IL-1 $\beta$ in the colonic mucosa, modulating the abundance of gut microbiota, and promoting the production and utilization of SCFAs in the colon (Zhang et al., 2020). However, positive control or dose-dependent effect analysis was not performed, which might require further validation. In addition, the structure of the correlation between polysaccharide administration and health outcomes, as well as the functional role of the polysaccharides themselves has not been examined in depth.

\section{Anti-Diabetes Activity}

Diabetes is a common disease with glucose metabolism disorder, which seriously affects human health around the world (Ye et al., 2017). Numerous ethnomedicinal studies supported the traditional use of $D$. officinale for clearing heat, nourishing "Yin", benefiting the stomach, and promoting body fluid, thereby leading $D$. officinale to become an essential medicine to treat "Xiao Ke" disease (Diabetes) for thousands of years (Yan et al., 2019b).

Over the past few years, the hypoglycemic effect of $D$. officinale has become an attractive research field. One study has confirmed that the administration of water extracts from the stems of $D$. officinale at the doses of 75,150, and a very high dose of $300 \mathrm{mg} / \mathrm{kg}$ for 12 weeks decreased serum insulin, TC, TG, LDL-c, and increase HDL-c in high-fat diet/streptozotocin (HFD/STZ) $(30 \mathrm{mg} / \mathrm{kg})$-induced diabetic mice in a dosedependent manner (Zeng et al., 2020). The possible mechanism of $D$. officinale water extracts can be associated with improving lipid transport and suppressing insulin resistance and fibrosis via EMT. Another study similarly found that a 4-weeks treatment with $D$. officinale water extracts at very high doses of 350 and $700 \mathrm{mg} / \mathrm{kg}$ elevated the liver glycogen synthesis, energy, and amino acid metabolism as well as taurine-mediated defense against oxidative stress in STZinduced diabetic mice (Zheng et al., 2017). It was found that the 


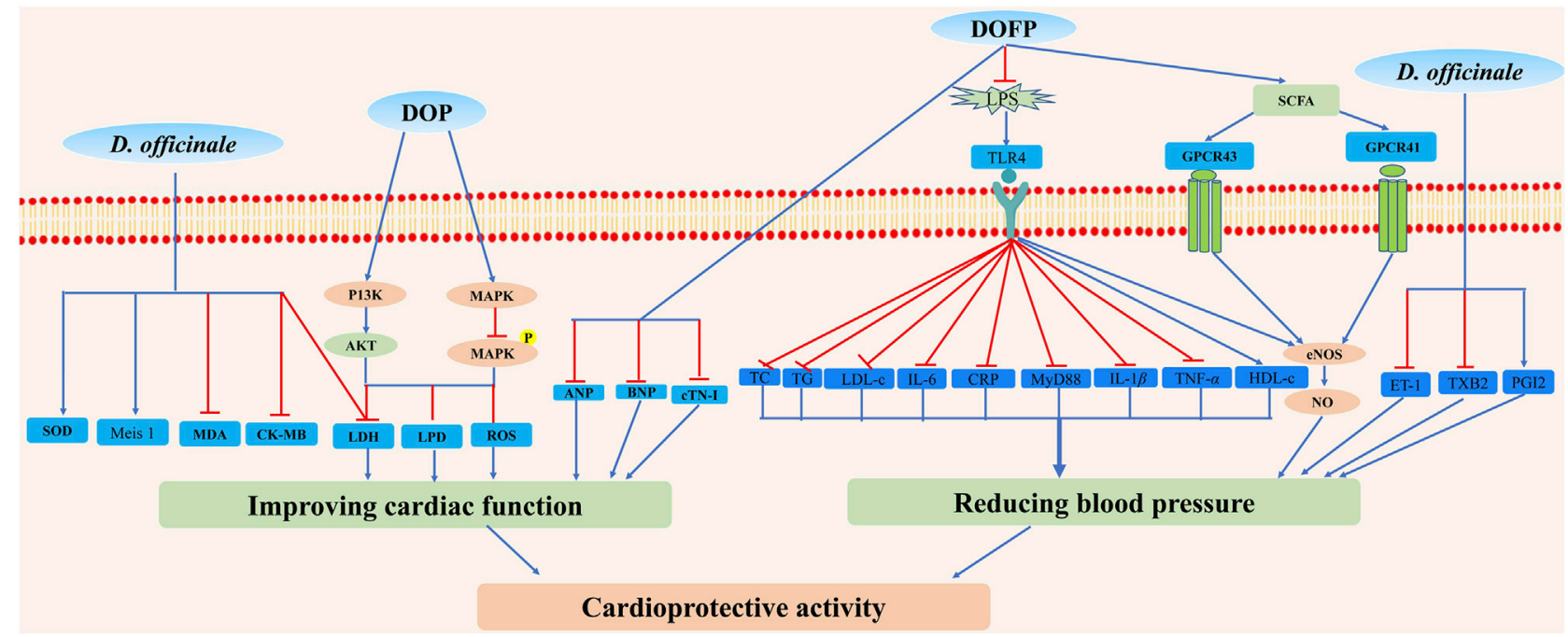

FIGURE 12 | Possible mechanisms for cardioprotective activity properties of $D$. officinale. D. officinale exhibited cardioprotective activity by improving cardiac function via inhibiting oxidative stress, inflammation, and by reducing blood pressure via inhibiting the activation of LPS/TLR4 signal pathway, decreasing ET-1 and TXB2 levels, and increasing SCFA and PGI2 levels.

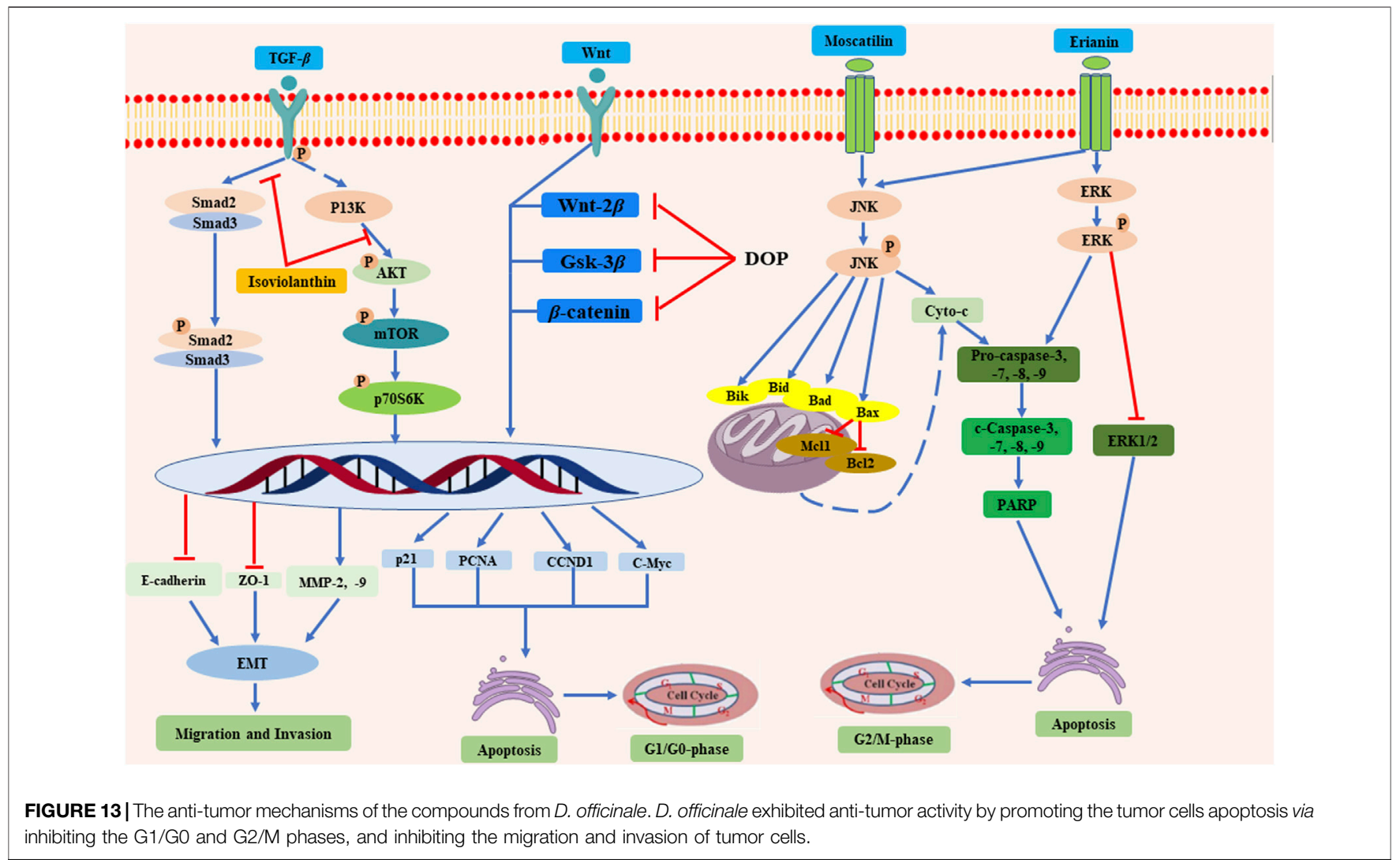

treatment of $D$. officinale stem's water extracts at very high doses of 10 and $20 \mathrm{~g} / \mathrm{kg}$ for 4 weeks ameliorated insulin resistance by decreasing toll-like receptors (TLRs) and inflammatory response in STZ-induced diabetic rats in comparison with the treatment of dimethyl biguanide (DMBG, $0.0042 \mathrm{~g} / \mathrm{kg}$ ) as a positive control (Zhao and Han 2018b). Moreover, it was reported that the administration of $D$. officinale at the doses of $0.2,0.4$, and $0.8 \mathrm{~g} / \mathrm{kg}$ for 8 weeks protected against diabetic kidney lesions 
in STZ-induced $(60 \mathrm{mg} / \mathrm{kg})$ rats via suppressing vascular endothelial growth factor (VEGF), glucose transporter 1 (GLUT-1), and connective tissue growth factor (CTGF) relative to the irbesartan $(17.5 \mathrm{mg} / \mathrm{kg})$-treated positive control (Chang et al., 2019). Additionally, a previous study also revealed that the hypoglycemic effect of the 3-months combined treatment of $D$. officinale $(10 \mathrm{~g} / \mathrm{d})$ and metformin $(0.5 \mathrm{~g} / \mathrm{d})$ was superior to the single-use ( $\mathrm{Wu}$ et al., 2017). However, these studies have important limitations-only one or two doses of $D$. officinale are used in these studies. In addition, the evaluation of $D$. officinale doses that are much higher, and it has no translational value from a therapeutic viewpoint.

It is evident that the hypoglycemic effect of $D$. officinale is closely related to the inhibition of $\alpha$-glucosidase and $\alpha$-amylase (Zhu et al., 2020). Notably, 3,4'-dihydroxy-5-methoxybibenzyl (2) and dihydroresveratrol (12) isolated from D. officinale extracts have been reported to exhibit hypoglycemic activity in an $\alpha$-glucosidase inhibitory assay with $\mathrm{IC}_{50}$ values of $36.05 \pm$ 0.67 and $159.59 \pm 0.86 \mu \mathrm{M}$, respectively, relative to the acarbose as a positive control $\left(\mathrm{IC}_{50}=152.86 \pm 1.43 \mu \mathrm{M}\right)$ (Liu et al., 2018). Likewise, 3,4-dihydroxy-4',5-dimethoxybibenzyl (3), 3,4,4'trihydroxy-5-methoxybibenzyl (8), dendrocandin U (15), $N$ - $p$ coumaroyltyramine (107), and $N$-trans-p-feruloyltyramine (108) have been identified as a-glucosidase inhibitors with IC $_{50}$ values of $199.5 \mu \mathrm{M}, 9.46 \mathrm{mM}, 403.4,0.4$ and $234.1 \mu \mathrm{M}$, respectively, compared with acarbose $\left(\mathrm{IC}_{50}=763.5 \mu \mathrm{M}\right)$. Furthermore, the inhibitory effect of 3,4-dihydroxy-4',5dimethoxybibenzyl (3) on a-amylase (an $\mathrm{IC}_{50}$ value of $5.99 \mathrm{mM}$ ) was weaker than acarbose $\left(\mathrm{IC}_{50}=0.12 \mu \mathrm{M}\right)$ (Chu et al., 2019). Several studies have demonstrated the definite hypoglycemic effect of $D$. officinale, while further investigations are required to identify the specific bioactive components responsible for this activity and clarify the hypoglycemic mechanism of $D$. officinale.

\section{Immunomodulatory Activity}

A large number of experiments have provided evidence for the immunomodulatory activity of $D$. officinale. Polysaccharide is the main active component for immunoregulation. Oral administration of $0.25 \%$ D. officinale polysaccharide DOW-5B $(\mathrm{w} / \mathrm{v})$ for 25 days displayed significant immunomodulatory effects via increasing the content of butyrate, immunoglobulin M (IgM), IL-10, and TNF-a in vivo (Li et al., 2020a). Another study also demonstrated that $D$. officinale polysaccharide DOP1-1 stimulated immunity by enhancing the level of nuclear factor kappa-B (NF- $\kappa \mathrm{B})$ while inhibiting the level of I $\mathrm{B} \alpha$ through TLR4 signaling (Huang et al., 2018). Moreover, it was found that D. officinale polysaccharides (FDP-1) treatments, ranging from 12.5 to $200 \mu \mathrm{g} / \mathrm{ml}$, exhibited immunomodulatory activity through increasing cell proliferation and NO and IL-1 $\beta$ production in a dose-dependent manner (Tian et al., 2019). Neither positive control nor dose-effect analysis in vivo was assessed in these studies. In addition, there is a general lack of systematic research on the relationship between immune activity and structure of $D$. officinale polysaccharides.

\section{Anti-Aging Activity}

The oral administration with a very high dose of $1 \mathrm{~g} / \mathrm{kg}$ of $D$. officinale juice and a very high dose of $0.32 \mathrm{~g} / \mathrm{kg}$ of $D$. officinale polysaccharide for 9 weeks exhibited an anti-aging effect in D-galactose-induced $(0.125 \mathrm{~g} / \mathrm{kg})$ aging mice, supported by the significantly increased contents of SOD, glutathione peroxidase (GSH-Px) and total antioxidant capacity (T-AOC) in serum, as well as the enhanced SOD level in heart, liver, kidney, and cerebrum (Liang et al., 2017). Similar to this study, the treatment with $D$. officinale polysaccharide (DOP) at the doses of 50 and $100 \mathrm{mg} / \mathrm{kg}$ for 4 weeks exhibited more potent antifatigue activity than Rhodiola rosea extract as a positive control in $\mathrm{BALB} / \mathrm{c}$ mice, as revealed by the increased TG (or fat) mobilization and the decreased lipid oxidation (LOD) and cell variability of $\mathrm{T}$ and $\mathrm{B}$ lymphocytes in the weight-loaded swimming test (Wei et al., 2017). However, the underlying mechanisms by which $D$. officinale's anti-aging effects remain unclear. Additionally, the current pharmacological research lacks component analysis and clinical pharmacological experiments.

\section{Anti-Osteoporosis Activity}

A previous study revealed that the administration of $D$. officinale water extracts at very high doses of 150,300 , and $600 \mathrm{mg} / \mathrm{kg}$ for 13 weeks prevented ovariectomy (OVX)-induced bone loss in Wistar rats by decreasing the levels of TG, alkaline phosphatase (ALP), bone glucose protein (BGP) while increasing acid phosphatase (ACP) and bone mineral density (BMD) in comparison with Xian-Ling-Gu-Bao capsule $(240 \mathrm{mg} / \mathrm{kg})$ as a positive control (Wang et al., 2018). Meanwhile, D. officinale water extract treatments $(10,40,80 \mu \mathrm{g} / \mathrm{ml})$ were found to suppress receptor activator expression of the nuclear factor $-\mathrm{\kappa B}$ ligand (RANKL)-induced osteoclastogenesis in RAW264.7 cells (Wang et al., 2018). In addition, D. officinale polysaccharide DOP treatments at very high doses of 200 or $400 \mu \mathrm{g} / \mathrm{ml}$ exhibited an antiosteoporosis effect through the activation of NRF2 signaling, thereby attenuating adipogenic differentiation and promoting osteogenic differentiation in BMSCs (Peng et al., 2019). Notably, no reports about the anti-osteoporosis effect of small molecule compounds from $D$. officinale have been documented so far.

\section{Protective Effects on Liver and Kidney}

One study has demonstrated that the treatment with $D$. officinale ethanol extracts at the doses of 4.375 and $17.5 \mathrm{mg} / \mathrm{kg}$ for 9 weeks prevented liver and kidney damage in hyperuricemic rats by suppressing the protein levels of NF- $\kappa \mathrm{B}$ and TLR4 compared with the model group $(0.15 \%$ adenine, $10 \%$ yeast extract, and $89.85 \%$ standard diet) (Lou et al., 2020). Likewise, another study revealed that $D$. officinale flower water extracts $(50,100,150$, and $200 \mathrm{mg} / \mathrm{kg}$ ) showed protective effects on alcohol-induced $(10 \mathrm{ml} / \mathrm{kg})$ liver injury by its anti-steatosis, anti-oxidative, and anti-inflammatory effects (Wu et al., 2020). However, additional evidence from randomized controlled trials is required to identify other regulatory mechanisms that may be responsible for the protective effects on liver and kidney. The bioactive constituents of these extracts also remain unknown. 


\section{Other Activities}

In addition to the bioactivities described above, $D$. officinale was also found to have other therapeutic effects, such as neuroprotective effect, anti-photoaging effect, and pulmonary protective function. For instance, in hypoxic-ischemic brain damage (HIBD) neonatal rat model (vehicle group, normal saline $=10 \mathrm{ml} / \mathrm{kg}$ ), the administration of aqueous extracts of D. officinale at the doses of 75,150 , and $300 \mathrm{mg} / \mathrm{kg}$ for 14 days suppressed the neuronal apoptosis by reducing cleaved caspase- 3 and Bax, increasing $\mathrm{Bcl}-2$, enhancing the expression of neurotrophic factors and $\mathrm{K}+-\mathrm{Cl}-$ cotransporter 2 (KCC2), and decreasing the expression of hypoxia-inducible factor- $1 \alpha$ (HIF-1 $\alpha$ ) and histone deacetylase 1 (HDAC1), leading to neuroprotective effects in neonatal rats against HIBD (Li and Hong, 2020b). D. officinale protocorm treatments at the doses of 10,25 , and $50 \mathrm{mg} / \mathrm{ml}$ exerted an anti-photoaging effect through decreasing erythema and protected skin from dryness by increasing CAT, SOD, and GSH-Px expression levels and decreasing thiobarbituric acid reactive substances (TBARS) and MMPs levels relative to the model group (UV irradiation) and positive control group (UV irradiation and a formulation of matrixyl) (Mai et al., 2019). In addition, D. officinale polysaccharides prevented lung injury by ameliorating cigarette smoke-induced mucus hypersecretion and viscosity by decreasing the expression of mucin-5AC (MUC5AC) mRNA and secretory protein in vitro and in vivo (Chen et al., 2020).

\section{QUALITY CONTROL}

The wild resources of $D$. officinale have gradually decreased, while the supply of artificially cultivated $D$. officinale has increased correspondingly. Consequently, wild resource collection has progressively become a non-mainstream, and the artificial cultivation mode occupies a dominant position in D. officinale industry ( $\mathrm{Ni}$ et al., 2018). According to the description in the Editorial Board of Chinese Pharmacopoeia (2020) edition, the peak area ratio of mannose to glucose, moisture content, total ash content, ethanol extract, and polysaccharide content should reach 2.4-8.0\%, less than $12.0 \%$, more than $6.0,6.5$, and $25.0 \%$ of $D$. officinale stem, respectively (China Pharmacopoeia Committee, 2020). However, the quality of $D$. officinale may be affected by regions, tissues, harvest time, cultivation techniques, growth years, endophytes, and others which may disturb the long growth cycle (Cheng $J$ et al., 2019). For instance, Li et al. (2017a) found that the contents of polysaccharides in $D$. officinale from Yunnan, Fujian, Jiangsu, and Zhejiang were variable ( $\mathrm{Li}$ et al., 2017b). Among them, the highest content of polysaccharides was $54.42 \%$ in Zhejiang, followed by $43.26 \%$ in Fujian (Li et al., 2017a). Previous studies have revealed that the contents of polysaccharides in stems, leaves, and flowers of $D$. officinale are $34.61 \%, 23.51 \%$, and $13.47 \%$, respectively (Cao et al., 2018). It was also found that the polysaccharide content of $D$. officinale is gradually increased during the entire flower-opening process from buds to full bloom, in which the polysaccharide content is the highest in the full bloom stage (13.75\%), followed by the micro bloom stage $(11.52 \%)$. In contrast, the lowest content appears in the bud stage (9.50\%) (Huang et al., 2017). In addition, $D$. officinale is usually planted on trees (fixed to the trunk with fine twine). Therefore, the polysaccharide content of D. officinale is significantly affected by different auxiliary tree species. Those planted on the evergreen tree Phoebe zhennan as the accessory hosts exhibit the highest polysaccharide content (37.8\%) substantially different from those grown on the Michelia ilsonii, Davidia nvolucrate and Taxus chinensis var. mairei (Gu and Xie, 2021). Moreover, the polysaccharide content of 5-yearold D. officinale stems is the highest, followed by 3-year-old, 4year-old, 2-year-old, and 1-year-old ones (Qin et al., 2017). Besides, endophytes play an important role in promoting the accumulation of polysaccharides. For example, DO14 (Pestalotiopsis sp.) isolated from D. officinale treated with $240 \mathrm{mg} / \mathrm{L}$ protein-polysaccharide fractions (PPF) can promote the accumulation of polysaccharides. This endophytic fungus could be used as biological fertilizer to improve the yield and quality of D. officinale (Zhu et al., 2018). In addition, exploiting suitable artificial-sheltered cultivation mode, screening the best cultivation substrate, and developing aseptic germination technology could be utilized to enhance the quality production of D. officinale in current agronomical practices (Cheng $\mathrm{Y}$ et al., 2019; Zuo et al., 2020).

It is well known that the polysaccharides' bioactivities vary from different sources, production regions, and cultivation conditions of $D$. officinale. Moreover, it has been reported that the bioactivities of $D$. officinale polysaccharides are related to their chemical characteristics and advanced structures. However, D. officinale polysaccharides are macromolecular compounds with large molecular weight and complex structure, thereby generating a great challenge to implement analytical technologies (Ma et al., 2018). Therefore, it is necessary to establish a safe and effective quality assessment method for the quality control and clinical application of D. officinale. Herein, the qualitative and quantitative analytic methods of $D$. officinale polysaccharides are summarized and discussed.

There are several rapid and accurate methods for quantitative estimation of natural polysaccharides and their different fractions in D. officinale (Wu et al., 2018a). Generally, the large D. officinale polysaccharides are acid hydrolyzed into oligosaccharides, and then LC-MS is used to separate and characterize the products efficiently. The previous results indicate that the variations in the mass values of different peaks present structural differences of various metabolized products. Moreover, MS can be used to explore the oligosaccharide hydrolysates of $D$. officinale polysaccharides in detail from the aspects of identity, structure, and properties (Ma et al., 2018). An oligosaccharidemarker approach by labeling them with fluorescence reagent paminobenzoic acid ethyl ester (ABEE) (Te-Man-ABEE and Pen-Man-ABEE) was recently applied for quality assessment of D. officinale polysaccharides using UHPLC-QTOF-MS (Wong et al., 2019). The results revealed that the two oligosaccharide markers exhibited a satisfactory linearity relationship with $D$. officinale polysaccharides $\left(R^{2} \geq 0.997\right)$ in the range of $0.68-16.02 \mu \mathrm{g}$. These markers also revealed satisfactory precision (relative standard deviation, RSD <7.0\%) and recovery (91.41-118.30\%) in unknown sample 
determination. It is speculated that the oligosaccharide-marker method is a simple, rapid, and reliable approach for the qualitative and quantitative determination of specific polysaccharides from $D$. officinale and other herb formulas (Wong et al., 2019).

Although single-component quality assessment can be used to control the quality of natural Chinese herbal medicine (Wei et al., 2020), the chemical compositions of D. officinale are complex. D. officinale contains a lot of effective nutritional compositions, including flavonoids, crude fiber, amino acids, proteins, and fat. These active components of $D$. officinale are affected by tissues and harvest times. A previous study found that the contents of flavonoids in the stems, leaves, and flowers of $D$. officinale were $0.052 \%, 0.251 \%$, and $1.835 \%$, respectively (Li et al., 2019a). Another research reported that the content of total flavonoids in the flowers of $D$. officinale is the highest at the full flowering stage (1.66\%) followed by the bract stage $(1.52 \%)$ and micro flowering stage (1.41\%) (Huang et al., 2017). It should be noted that the contents of five representative flavonoid glucosides from $D$. officinale in 25 batches with different sources were determined by UHPLC-ESI-MS/MS, where principal component analysis (PCA) and hierarchical cluster analysis (HCA) were applied (Ye et al., 2017). The content of crude fiber in the autumn stem is $59.7 \%$ higher than that in the spring stem, and the fiber in the autumn leaf is $122.9 \%$ higher than that in the spring leaf ( $\mathrm{Li}$ et al., 2017a). The total protein content of $D$. officinale stems in autumn is $10.9 \%$ higher than that in spring, while that of the leaves in autumn is $9.3 \%$ higher than that in spring. The results also revealed that the total protein content in the leaves is higher than that in the stems, and the ratio of total protein in the autumn leaves is $67.03 \mathrm{mg} / \mathrm{g}$, which is $31.4 \%$ higher than that in the autumn stems $(51.02 \mathrm{mg} / \mathrm{g})$. The content of fat in the stems and leaves of $D$. officinale ranges from 10.0 to $15.0 \mathrm{mg} / \mathrm{g}$. The average content of fat in the leaves $(13.90 \mathrm{mg} / \mathrm{g})$ is slightly higher than that in the stems $(11.50 \mathrm{mg} / \mathrm{g})$ (Liao et al., 2018). In particular, Wu and Feng (2019) revealed that the content of polysaccharides is the highest in those samples collected from October to the following March (Wu and Feng, 2019). Yu et al. (2014) found that it is more reasonable to harvest D. officinale at biennials pre-bloom than at specific harvesting months according to the content of polysaccharides ( $\mathrm{Xu}$ et al., 2021). According to the Editorial Board of Chinese Pharmacopoeia (2020) edition, however, D. officinale should be harvested from November to the following March (China Pharmacopoeia Committee, 2020).

Additionally, there are some noteworthy scientific gaps, which can be resolved from the following aspects. First, the genuine, defective, and counterfeit varieties of $D$. officinale are mixed together, so there is an urgent need to breed varieties with better agronomic characters, high yield, high quality, and intense stress resistance. (Guo et al., 2019). Second, it is also an effective way to ensure the quality of $D$. officinale by controlling pesticide residues and using endophytes to control diseases and pests (Yu et al., 2014; Zhou et al., 2018). Third, at present, chemical methods are primarily used to evaluate the quality of $D$. officinale, while the quality evaluation of traditional Chinese medicine is closely related to its biological activity.
Therefore, the evaluation methods are suggested to be improved by combining chemical approaches and bioassays, providing a foundation for the industrial production and clinic use of D. officinale (Wei et al., 2020).

\section{SAFETY}

The stems and leaves of $D$. officinale were approved by National Health and Family Planning Commission (NHFPC) of People's Republic (PR) of China to be utilized as a novel food material on Jan 15, 2013 and Jan 15, 2017 (National Health and Family Planning Commission of the People's Republic of China, 2013; National Health and Family Planning Commission of the People's Republic of China, 2017), respectively. Therefore, several safety studies of $D$. officinale have been performed. It has been reported that acute toxicity test $(12.0 \mathrm{~g} / \mathrm{kg})$, genetic toxicity tests (Ames test, micronucleus test of bone marrow, and sperm shape abnormality test in mice) $(1,000,2000$, and $4,000 \mathrm{mg} / \mathrm{kg})$, and 90 -days feeding test $(1.08,1.67$, and $5.00 \mathrm{~g} / \mathrm{kg}$ ) in rats were employed to assess the safety of the stems from $D$. officinale. These results indicated that $D$. officinale was a type of health food product without noticeable toxicity, genetic toxicity, and mutagenicity within the range of the test doses (Li Z. et al., 2019). Moreover, oral administration with D. officinale stems at the doses of $25,1,250$, and $2,500 \mathrm{mg} / \mathrm{kg}$ did not exhibit any apparent effect on pregnant rats or deformity effect on fetal rats (Qin et al., 2019). Likewise, oral administration with the leaves and flowers of D. officinale at the doses of $0,2.0$, 4.0 , and $6.4 \mathrm{~g} / \mathrm{kg}$ for 90 days did not exhibit apparent adverse effects on sperm quality and testicular tissue morphology in parent and offspring rats (Fu et al., 2017; Fu et al., 2020a). Besides, D. officinale flowers $(0,2.0,6.4 \mathrm{~g} / \mathrm{kg})$ had no apparent adverse effects on pregnant and offspring rats before birth (Fu et al., 2020b).

D. officinale is considered to have edible and medicinal values. However, due to its thermal tonic property, it is prohibited for patients with wind-heat cold, dampness, and allergies, teenagers, and pregnant women. According to the Pharmacopoeia of the People's Republic of China (China Pharmacopoeia Committee, 2020), the dosage of 6-12 $\mathrm{g} / \mathrm{d}$ of $D$. officinale is appropriate, and intake of trace elements recommended by the Food and Drug Administration of the United States will not induce poisonous effects.

\section{CONCLUSION AND FUTURE PROSPECTS}

D. officinale, as a medicinal or food homologous product, plays a crucial role in healthcare. This study summarizes and updates the botany, traditional uses, bioactive components, pharmacology, quality control, and safety of $D$. officinale. Available data indicate that over 120 compounds have been isolated and identified from $D$. officinale, including polysaccharides, bibenzyls, flavonoids, alkaloids, phenanthrenes, etc. D. officinale is associated with multiple beneficial pharmacological properties, such as cardioprotective, anti-tumor, gastrointestinal protective, 
anti-diabetes, anti-aging, and anti-osteoporosis activities. Furthermore, it is evident that D. officinale is a non-toxic, which can be listed as a toxicologically safe functional food. However, its clinical applications has been rarely described, and critical improvements are still required for its industrial applications.

Firstly, phytochemical studies have demonstrated that $D$. officinale mainly contains polysaccharides, bibenzyls, phenanthrenes, and flavonoids while little is known about the analysis and function of organic compounds such as protein and fatty acid. Growing evidence has shown that structure-based drug design plays a vital role in developing novel drugs, and a series of strategies can be adopted to obtain effective therapeutic drugs. Further studies need to be conducted to isolate and identify more compounds from $D$. officinale with novel structures, emphasizing on bioactivity-guided, structurally modified, and chemically synthesized molecules. Besides, most of the D. officinale containing health products are mainly derived from its stems rich in chemical compounds, while non-medicinal parts are rarely exploited. Therefore, it may be interesting to extend the research to the non-medicinal parts of the inexpensive flowers, leaves, and roots of $D$. officinale to ensure the fully utilization of its edible and medicinal values (Zhang et al., 2017a).

Second, D. officinale is traditionally used to relieve fatigue, nourish "Yin", heart, and stomach, and expel evil heat, which is closely related to its preventive effects on cardiac, gastrointestinal and diabetes diseases according to modern pharmacology. Pharmacological research of the cardioprotective, gastrointestinal tract and anti-diabetes protective effects of $D$. officinale mainly concentrates on its crude extracts and polysaccharides. However, the optimal dose, constituents, and side effects of $D$. officinale are not assessed. Besides, there is a lack of in-depth study on the mechanism of action of D. officinale monomeric compounds or the specific mechanism of $D$. officinale in animals is not comprehensive enough. Therefore, the highquality and well-designed in vivo, in vitro, and clinical studies are encouraged to be carried out and to explore the molecular mechanisms and relationship between active chemical constituents and potential cardioprotective, gastrointestinal tract regulatory and anti-diabetes effects.

Third, the dosage of $D$. officinale used in previous studies were different (ranging from $4.375 \mathrm{mg} / \mathrm{kg}$ to $20 \mathrm{~g} / \mathrm{kg}$ ). It is not possible to define an exact upper cut-off dose, and the test dose needs to be pharmacologically relevant. In many cases, $100-200 \mathrm{mg} / \mathrm{kg}$ extracts for in vivo studies should be assumed as the upper limit for meaningful pharmacological studies. For pure compounds, a much lower dose range (e.g., 30-50 $\mu \mathrm{M}$ ) should be considered for in vitro studies (Heinrich et al., 2020). In some

\section{REFERENCES}

Cao, X. Y., Tang, Y. N., Jiang, X. M., Shao, W., and Gao, D. M. (2018). Study on contents and antioxidant activity of polysaccharides in different parts of Dendrobium officinale Kimura et Migo. Food Drug 20, 227-230. doi:10.3969/j.issn.1672-979X.2018.03.015

Chang, J., Zhou, Y., Cong, G., Guo, H., Guo, Y., Lu, K., et al. (2019). Dendrobium Candidum Protects against Diabetic Kidney Lesions through Regulating cases, the pharmacological activity of $D$. officinale is present only with doses that might be too high for clinical use. According to the Chinese Pharmacopoeia, 6-12 g/day administration of $D$. officinale extract is common for human, but any clinical application at such doses should be accompanied with conservative safety insurance. Besides, the acute toxicity and sub-toxicity assessments of $D$. officinale were mostly carried out based on animal experiments. Furthermore, comprehensive placebo-controlled and double-blind clinical trials are necessary to provide sufficient evidence ensuring drug efficacy and patient safety.

Finally, D. officinale possesses various biological activities, which has been applied as health care medicine, health food, and health tea. In addition, with the development of analytical techniques and quality control methods, such as the improvement and update in chromatography techniques and molecular identification methods, new quality markers and quality control measures are likely to be adopted for better quality assessment of Chinese herbal medicine in the future (Leong et al., 2020).

In conclusion, D. officinale is one of the most popular medicinal and food homologous products in China. Modern pharmacology investigations have revealed its cardioprotective, gastrointestinal protective, anti-diabetes, and antiaging effects, which robustly support its traditional application in nourishing "Yin", heart, and stomach, expelling evil heat, and relieving fatigue. This paper provides a full-scale review about the progress of botany, traditional uses, phytochemistry, pharmacology, quality control, and toxicology of D. officinale. The information summarized in this work can provide a foundation for further applying the medicinal and edible value of $D$. officinale in the future.

\section{AUTHOR CONTRIBUTION}

WC collated documents and wrote the manuscript; JL and JZ helped to perform the arrangement of tables and pictures; JW and LY helped to check chemical structure formula; LQ and BZ contributed significantly to analysis and manuscript preparation. All authors have read and approved the final version of the manuscript.

\section{FUNDING}

This work was supported by the National Natural Science Foundation of China (82003896).

Vascular Endothelial Growth Factor, Glucose Transporter 1, and Connective Tissue Growth Factor Expression in Rats. J. Cel. Biochem. 120, 13924-13931. doi: $10.1002 /$ jcb. 28666

Chen, H., Li, X., Xu, Y., Lo, K., Zheng, H., Hu, H., et al. (2018). Study on the Polar Extracts of Dendrobium Nobile, D. Officinale, D. Loddigesii, and Flickingeria Fimbriata: Metabolite Identification, Content Evaluation, and Bioactivity Assay. Molecules 23, 1185-1194. doi:10.3390/ molecules23051185 
Chen, R., Liang, Y., Ip, M. S. M., Zhang, K. Y., and Mak, J. C. W. (2020). Amelioration of Cigarette Smoke-Induced Mucus Hypersecretion and Viscosity by Dendrobium Officinale Polysaccharides In Vitro and In Vivo. Oxid. Med. Cel. Longev. 2020, 8217642-8217651. doi:10.1155/2020/8217642

Chen, Y., Wang, Y., Lyu, P., Chen, L., Shen, C., and Sun, C. (2019). Comparative Transcriptomic Analysis Reveal the Regulation Mechanism Underlying MeJAInduced Accumulation of Alkaloids in Dendrobium Officinale. J. Plant Res. 132, 419-429. doi:10.1007/s10265-019-01099-6

Cheng, J., Dang, P.-P., Zhao, Z., Yuan, L.-C., Zhou, Z.-H., Wolf, D., et al. (2019). An Assessment of the Chinese Medicinal Dendrobium Industry: Supply, Demand and Sustainability. J. Ethnopharmacology 229, 81-88. doi:10.1016/ j.jep.2018.09.001

Chu, C., Li, T., Pedersen, H. A., Kongstad, K. T., Yan, J., and Staerk, D. (2019). Antidiabetic Constituents of Dendrobium Officinale as Determined by HighResolution Profiling of Radical Scavenging and $\alpha$-glucosidase and $\alpha$-amylase Inhibition Combined with HPLC-PDA-HRMS-SPE-NMR Analysis. Phytochemistry Lett. 31, 47-52. doi:10.1016/j.phytol.2019.03.002

Committee for the Pharmacopoeia of PR China (2015). Pharmacopoeia of the People's Republic of China, Part 1. Beijing, China: China Medical Science Press, 295-296.

Cui, Y. D., Lu, Y. L., Zhao, Y. M., Liu, M. X., and Zhang, G. G. (2019). Isolation and identification of chemical constituents from Dendrobium officinale Kimura et Migo. J. Shenyang. Pharm. Univer. 36, 7-11. doi:10.14066/j.cnki.cn21-1349/ r.2019.01.002

Dou, M.-M., Zhang, Z.-H., Li, Z.-B., Zhang, J., and Zhao, X.-Y. (2016). Cardioprotective potential of Dendrobium officinale Kimura et Migo against myocardial ischemia in mice. Mol. Med. Rep. 14, 4407-4414. 2016. doi:10.3892/ mmr.2016.5789

Editorial Board of Chinese Pharmacopoeia (2020). Chinese Pharmacopoeia, Vol. 1. Beijing, China: China Medical Science Press, 94-97, pp. 295-296.

Flora of China Editorial Committee (2009). Flora of the People's Republic of China, Part 25 (English). Beijing, China: Science Press, 139.

Fu, J. Y., Song, Y. H., He, J. W., Zhu, Z. J., Song, S., and Xia, Y. (2017). A Study on the Effects of Dendrobium Officinale Leaves on Sperm Quality and Testicular Tissue Morpholohy in Parent and Offspring Rats. Pre. Med. 29, 782-789. doi:10.1002/elan.201600787

Fu, J. Y., Song, Y. H., Zhang, Y. Y., Zhu, Z. J., He, J. W., and Xia, Y. (2020a). Effects of Dendrobium Officinale Flowers on Testivular Tissue and Sperm Quality in Parent and Offspring Rats. Pre. Med. 32, 442-445. doi:10.19485/ j.cnki.issn2096-5087.2020.05.003

Fu, J. Y., Xia, Y., Zhang, Y. Y., Cai, D. L., He, J. W., and Song, Y. H. (2020b). Toxicity of Dendrobium Officinale Flowers to Pregnant Rats and Offspring Rats before Birth. Pre. Med. 32, 1000-1003. doi:10.19485/j.cnki.issn2096-5087.2020.10.007

Fu, L. G. (1992). China Plant Red Data Book Rare and Endangered Plants. Beijing, China: Science Press, 492-493.

Gong, X. Y., Jiang, S. M., Tian, H. Y., Xiang, D., and Zhang, J. C. (2020). Polyphenols in the Fermentation Liquid of Dendrobium Candidum Relieve Intestinal Inflammation in Zebrafish through the Intestinal MicrobiomeMediated Immune Response. Front. Immunol. 11, 1542-1558. doi:10.3389/ fimmu.2020.01542

Gu, H. Y., and Xie, K. P. (2021). Study on Epiphytic Cultivation Techniques of Dendrobium Officinale under Forestin in Emei Mountain. S. Chin. For. Sci. 49, 40-43. doi:10.16259/j.cnki.36-1342/s.2021.01.010

Guo, L., Qi, J., Du, D., Liu, Y., and Jiang, X. (2020a). Current Advances of Dendrobium Officinale Polysaccharides in Dermatology: a Literature Review. Pharm. Biol. 58, 664-673. doi:10.1080/13880209.2020.1787470

Guo, Y. (2020b). Efficacy of the Tiepishihu Yangwei Quwei Mixture on Intestinal Metathesis of Gastric Mucosa. Clin. J. Chin. Med. 12, 81-83. doi:10.3969/ j.issn.1674-7860.2020.28.029

Guo, Z., Zhou, Y., Yang, J., and Shao, X. (2019). Dendrobium Candidum Extract Inhibits Proliferation and Induces Apoptosis of Liver Cancer Cells by Inactivating Wnt/ $\beta$-Catenin Signaling Pathway. Biomed. Pharmacother. 110, 371-379. doi:10.1016/j.biopha.2018.11.149

He, L., Su, Q., Bai, L., Li, M., Liu, J., Liu, X., et al. (2020). Recent Research Progress on Natural Small Molecule Bibenzyls and its Derivatives in Dendrobium Species. Eur. J. Med. Chem. 204, 112530-112546. doi:10.1016/j.ejmech.2020.112530

Heinrich, M., Appendino, G., Efferth, T., Fürst, R., Izzo, A. A., Kayser, O., et al. (2020). Best Practice in Research - Overcoming Common Challenges in
Phytopharmacological Research. J. Ethnopharmacology 246, 112230-112237. doi:10.1016/j.jep.2019.112230

Huang, S., Chen, F., Cheng, H., and Huang, G. (2020). Modification and Application of Polysaccharide from Traditional Chinese Medicine Such as Dendrobium Officinale. Int. J. Biol. Macromolecules 157, 385-393. doi:10.1016/ j.ijbiomac.2020.04.141

Huang, X. H., Wang, Z. H., Li, J., Miao, A. Q., and Ye, Q. S. (2017). Comparative Analysis of Quality Properties and Main Nutrients in Dendrobium Flowers during Different Flowering Phases. Chin. J. Trop. Crop 38, 45-52.

Huang, Y.-P., He, T.-B., Cuan, X.-D., Wang, X.-J., Hu, J.-M., and Sheng, J. (2018). $1,4-\beta$-d-Glucomannan from Dendrobium Officinale Activates NF-Kb via TLR4 to Regulate the Immune Response. Molecules 23, 2658-2672. doi:10.3390/ molecules 23102658

Jiao, C., Song, C., Zheng, S., Zhu, Y., Jin, Q., Cai, Y., et al. (2018). Metabolic Profiling of Dendrobium Officinale in Response to Precursors and Methyl Jasmonate. Ijms 19, 728-746. doi:10.3390/ijms19030728

Ke, Y., Zhan, L. H., Lu, T. T., Zhou, C., Chen, X., Dong, Y. J., et al. (2020). Polysaccharides of Dendrobium Officinale Kimura \& Migo Leaves Protect against Ethanol-Induced Gastric Mucosal Injury via the AMPK/mTOR Signaling Pathway In Vitro and Vivo. Front. Pharmacol. 11, 526349-526363. doi:10.3389/fphar.2020.526349

Lee, E., Han, A.-R., Nam, B., Kim, Y.-R., Jin, C. H., Kim, J.-B., et al. (2020). Moscatilin Induces Apoptosis in Human Head and Neck Squamous Cell Carcinoma Cells via JNK Signaling Pathway. Molecules 25, 901-912. doi:10.3390/molecules25040901

Lei, Z. X., Zhou, C. H., Ji, X. Y., Wei, G., Huang, Y. C., Yu, W. X., et al. (2018). Transcriptome Analysis Reveals Genes Involved in Flavonoid Biosynthesis and Accumulation in Dendrobium Officinale from Different Locations. Sci. Rep. 8, 6373-6388. doi:10.1038/s41598-018-24751-y

Leong, F., Hua, X., Wang, M., Chen, T. K., Song, Y. L., Tu, P. F., et al. (2020). Quality Standard of Traditional Chinese Medicines: Comparison between European Pharmacopoeia and Chinese Pharmacopoeia and Recent Advances. Chin. Med. 15, 76-95. doi:10.1186/s13020-020-00357-3

Li, B., He, X., Jin, H.-Y., Wang, H.-Y., Zhou, F.-C., Zhang, N.-Y., et al. (2021). Beneficial Effects of Dendrobium Officinale on Metabolic Hypertensive Rats by Triggering the Enteric-Origin SCFA-Gpcr43/41 Pathway. Food Funct. 12, 5524-5538. doi:10.1039/d0fo02890h

Li, D.-l., Zheng, X.-l., Duan, L., Deng, S.-w., Ye, W., Wang, A.-h., et al. (2017a). Ethnobotanical Survey of Herbal tea Plants from the Traditional Markets in Chaoshan, China. J. Ethnopharmacology 205, 195-206. doi:10.1016/ j.jep.2017.02.040

Li, F., Wei, Y., and Chen, Y. J. (2019a). Study on the content of flavonoids in stems, leaves and flowers of Dendrobium officinale Kimura et Migo and its antioxidant activity In Vitro. Acta Chin. Med. 34, 1020-1023. doi:10.16368/j.issn.16748999.2019.05.242

Li, L. Y., Ding, Q., and Sun, P. F. (2017b). Study on Quality of Dendrobium Officinale in Different Regions. Mod. Chin. Med. 19, 1702-1707. doi:10.13313/ j.issn.1673-4890.2017.12.009

Li, M., Yue, H., Wang, Y., Guo, C., Du, Z., Jin, C., et al. (2020a). Intestinal Microbes Derived Butyrate Is Related to the Immunomodulatory Activities of Dendrobium Officinale Polysaccharide. Int. J. Biol. Macromolecules 149, 717-723. doi:10.1016/j.ijbiomac.2020.01.305

Li, X. L., and Hong, M. (2020b). Aqueous Extract ofDendrobium Officinaleconfers Neuroprotection against Hypoxic-ischemic Brain Damage in Neonatal Rats. Kaohsiung J. Med. Sci. 36, 43-53. doi:10.1002/kjm2.12139

Li, Z., Liu, M., Hu, J., and Qin, G. H. (2019b). Effects of Dendrobium Officinale on Blood Biochemical Indexes of Rats. J. Food Safe. Qual. 1, 3579-3583.

Liang, C. Y., Liang, Y. M., Liu, H. Z., Zhu, D. M., Hou, S. Z., Wu, Y. Y., et al. (2017). Effect of Dendrobium Officinale on D-Galactose-Induced Aging Mice. Chin. J. Integr. Med., 1-9. doi:10.1007/s11655-016-2631-x2017

Liang, J., Li, H., Chen, J., He, L., Du, X., Zhou, L., et al. (2019). Dendrobium Officinale Polysaccharides Alleviate colon Tumorigenesis via Restoring Intestinal Barrier Function and Enhancing Anti-tumor Immune Response. Pharmacol. Res. 148, 104417-104429. doi:10.1016/j.phrs.2019.104417

Liang, J., Zeng, Y., Wang, H., and Lou, W. (2018). Extraction, Purification and Antioxidant Activity of Novel Polysaccharides from Dendrobium Officinale by Deep Eutectic Solvents. Nat. Product. Res. 33, 3248-3253. doi:10.1080/ 14786419.2018.1471480 
Liang, K. L., Fang, P., Shi, Q. Q., Su, J., Li, B., Chen, S. H., et al. (2018). [Antihypertensive Effect and Mechanism of Dendrobium Officinale Flos on High-Blood Pressure Rats Induced by High Glucose and High Fat Compound Alcohol]. Zhongguo Zhong Yao Za Zhi 43, 147-153. doi:10.19540/ j.cnki.cjcmm.20171027.020

Liao, X. Y., Xu, H. M., Liu, P., Chen, C. J., Li, X. K., and Huang, J. Y. (2018). Analysis on the Basic Nutritional Components of Dendrobium Officinale "Yanshangxian. J. Food Sci. Tech. 36, 61-67. doi:10.1200/jco.2018.78.4652

Liu, C.-Z., Chen, W., Wang, M.-X., Wang, Y., Chen, L.-Q., Zhao, F., et al. (2020). Dendrobium officinale Kimura et Migo and American ginseng mixture: A Chinese herbal formulation for gut microbiota modulation. Chin. J. Nat. Medicines 18, 446-459. doi:10.1016/s1875-5364(20)30052-2

Liu, M. X., Cui, Y. D., Deng, B. W., Shi, S., Zhang, C. Y., and Zhang, G. G. (2018). Isolation and identification of chemical constituents from Dendrobium officinale Kimura et Migo. J. Shenyang. Pharm. Univer. 35, 739-743. doi:10.14066/j.cnki.cn21-1349/r.2018.09.007

Liu, Y.-T., Hsieh, M.-J., Lin, J.-T., Chen, G., Lin, C.-C., Lo, Y.-S., et al. (2019). Erianin Induces Cell Apoptosis through ERK Pathway in Human Nasopharyngeal Carcinoma. Biomed. Pharmacother. 111, 262-269. doi:10.1016/j.biopha.2018.12.081

Lou, X. J., Wang, Y. Z., Lei, S. S., He, X., Lu, T. T., Zhan, L. H., et al. (2020). Beneficial Effects of Macroporous Resin Extract of Dendrobium Officinale Leaves in Rats with Hyperuricemia Induced by a High-Purine Diet. Evid. Based. Complement. Alternat. Med. 2020, 3086106-3086115. doi:10.1155/2020/3086106

Luo, Y., Ren, Z., Du, B., Xing, S., Huang, S., Li, Y., et al. (2019). Structure Identification of ViceninII Extracted from Dendrobium Officinale and the Reversal of TGF-B1-Induced Epithelial-Mesenchymal Transition in Lung Adenocarcinoma Cells through TGF- $\beta /$ Smad and PI3K/Akt/mTOR Signaling Pathways. Molecules 24, 144-159. doi:10.3390/molecules24010144

Lv, C. G., Yang, J., Kang, C. Z., Li, Z. H., M, Z. H., G, L. P., et al. (2017). Determination of 10 Flavonoids by UPLC-MS/MS and Analysis of Polysaccharide Contents and Compositions in Dendrobium Officinale Caulis from Different Habitats. Chin. J. Exper. Tradi. Med. Formu. 23, 47-52. doi:10.13422/j.cnki.syfjx.2017170047

Ma, H., Zhang, K., Jiang, Q., Dai, D., Li, H., Bi, W., et al. (2018). Characterization of Plant Polysaccharides from Dendrobium Officinale by Multiple Chromatographic and Mass Spectrometric Techniques. J. Chromatogr. A 1547, 29-36. doi:10.1016/j.chroma.2018.03.006

Mai, Y., Niu, Z., He, W., Lai, X., Huang, S., and Zheng, X. (2019). The Reparative Effect of Dendrobium Officinale Protocorms against Photodamage Caused by UV-Irradiation in Hairless Mice. Biol. Pharm. Bull. 42, 728-735. doi:10.1248/bpb.b18-00901

National Health and Family Planning Commission of the People's Republic of China (2013). NHFPC-approved Seven New Food Materials. Announcement No. 1, 2013.

National Health and Family Planning Commission of the People's Republic of China (2017). NHFPC-approved Seven New Food Materials. Announcement No. 1, 2017.

Ni, Z., Chen, Z., Bai, R., and Tang, F. (2018). Determination of Trace Elements in Dendrobium Officinale Cultivated in Various Conditions. Anal. Lett. 51, 648-658. doi:10.1080/00032719.2017.1345931

Peng, H., Yang, M., Guo, Q., Su, T., Xiao, Y., and Xia, Z. Y. (2019). Dendrobium Officinale Polysaccharides Regulate Age-Related Lineage Commitment between Osteogenic and Adipogenic Differentiation. Cell. Prolif. 52, 12624-12633. doi: $10.1111 /$ cpr.12624

Peng, L.-Q., Dong, X., Zhen, X.-T., Yang, J., Chen, Y., Wang, S.-L., et al. (2020). Simultaneous Separation and Concentration of Neutral Analytes by Cyclodextrin Assisted Sweeping-Micellar Electrokinetic Chromatography. Analytica Chim. Acta 1105, 224-230. doi:10.1016/j.aca.2020.01.037

Qin, G. H., Liu, M., Wang, W., Hu, J. X., and Li, Z. (2019). Effects of Dendrobium Officinale on Pregnant Rats and Embryonic Development of Offspring Mice. J. Food Safe. Qual. 10, 3971-3974.

Qin, Z. F., Tan, X. Y., Ning, H. J., H, J., Miao, Y. X., and Zhang, X. Q. (2017). Quantification and Characterization of Polysaccharides from Different Aged Dendrobium Officinale Stems. Food Sci. 39, 189-193. doi:10.7506/spkx10026630-201806030

Ren, G., Chen, Y. T., Ye, J. B., Zhong, G. Y., Xiao, C. Y., Deng, W. Z., et al. (2020a). Phytochemical Investigation of Leaves of Dendrobium Officinale. Chin. Trad. Herb. Drug 55, 3637-3644. doi:10.7501/j.issn.0253-2670.2020.14.005
Ren, G., Deng, W. Z., Xie, Y. F., Wu, C. H., Li, W. Y., Xiao, C. Y., et al. (2020b). Bibenzyl Derivatives from Leaves of Dendrobium Officinale. Nat. Prod. Comm. 15, 1-5. doi:10.1177/1934578x20908678

Ren, Z., Ji, X., Jiao, Z., Luo, Y., Zhang, G. Q., Tao, S., et al. (2020c). Functional Analysis of a Novel C-Glycosyltransferase in the Orchid Dendrobium Officinale. Hortic. Res. 7, 111-128. doi:10.1038/s41438-020-0330-4

Ren, Z. Y., Qiu, F. N., Wang, Y. J., Yu, W. X., Liu, C. X., Sun, Y. Y., et al. (2020d). Network Analysis of Transcriptome and LC-MS Reveals a Possible Biosynthesis Pathway of Anthocyanins in Dendrobium Officinale. Biomed. Res. Int. 2020, 6512895-65129906. doi:10.1155/2020/6512895

Shi, X.-D., Yin, J.-Y., Cui, S. W., Wang, Q., Wang, S.-Y., and Nie, S.-P. (2020). Comparative Study on Glucomannans with Different Structural Characteristics: Functional Properties and Intestinal Production of Short Chain Fatty Acids. Int. J. Biol. Macromolecules 164, 826-835. doi:10.1016/ j.ijbiomac.2020.07.186

Su, J., Wang, T., Yan, M. Q., Yu, J. J., Xu, J., Zhuge, R. C., et al. (2021). Effect of Dendrobium Officinale Superfine Powder on Overeating Greasy-Induced Metabolic Hypertension in Rats. China. J. Chin. Mater. Med. 2021, 1-11. doi:10.19540/j.cnki.cjcmm.20201027.403

Teixeira, D. S. J. A., and Ng, T. B. (2017). The Medicinal and Pharmaceutical Importance of Dendrobium Species. Appl. Microbiol. Biotechnol. 101, 2227-2239. doi:10.1007/s00253-017-8169-9

Tian, W., Dai, L., Lu, S., Luo, Z., Qiu, Z., Li, J., et al. (2019). Effect of Bacillus Sp. DU-106 Fermentation on Dendrobium Officinale Polysaccharide: Structure and Immunoregulatory Activities. Int. J. Biol. Macromolecules 135, 1034-1042. doi:10.1016/j.ijbiomac.2019.05.203

Wang, Q., Zi, C. T., Wang, J., Wang, Y. N., Huang, Y. W., Fu, X. Q., et al. (2018). Dendrobium Officinale Orchid Extract Prevents Ovariectomy-Induced Osteoporosis In Vivo and Inhibits RANKL-Induced Osteoclast Differentiation In Vitro. Front. Pharmacol. 8, 966-978. doi:10.3389/ fphar.2017.00966

Wei, W., Li, Z.-P., Zhu, T., Fung, H.-Y., Wong, T.-L., Wen, X., et al. (2017). Antifatigue Effects of the Unique Polysaccharide Marker of Dendrobium Officinale on BALB/c Mice. Molecules 22, 155-166. doi:10.3390/molecules22010155

Wei, X. C., Cao, B., Luo, C. H., Huang, H. Z., Tan, P., Xu, X. R., et al. (2020). Recent Advances of Novel Technologies for Quality Consistency Assessment of Natural Herbal Medicines and Preparations. Chin. Med. 15, 56-78. doi:10.1186/s13020-020-00335-9

Wei, Y., Wang, L. W., Wang, D. J., Wang, D., Wen, C. W., and Han, B. (2018). Characterization and Anti-tumor Activity of a Polysaccharide Isolated from Dendrobium Officinale Grown in the Huoshan County. Chin. Med. 13, 47-57. doi:10.1186/s13020-018-0205-x

Wong, T.-L., Li, L.-F., Zhang, J.-X., Bai, S.-P., Zhou, L.-S., Fung, H.-Y., et al. (2019). Oligosaccharide-marker Approach for Qualitative and Quantitative Analysis of Specific Polysaccharide in Herb Formula by Ultra-high-performance Liquid Chromatography-Quadrupole-Time-Of-Flight Mass Spectrometry: Dendrobium Officinale, a Case Study. J. Chromatogr. A 1607, 460388-460396. doi:10.1016/j.chroma.2019.460388

Wu, D.-T., Guo, H., Lin, S., Lam, S.-C., Zhao, L., Lin, D.-R., et al. (2018a). Review of the Structural Characterization, Quality Evaluation, and Industrial Application of Lycium Barbarum Polysaccharides. Trends Food Sci. Tech. 79, 171-183. doi:10.1016/j.tifs.2018.07.016

Wu, J. Y., and Feng, Y. (2019). The Determination and Comparison of Main Components of Dendrobium Officinale in Different Harvesting Periods. Chin. J. Ethnomed. Ethnophar. 2, 39-42. 1007-8517(2019)10-0039-04

Wu, J., Zhuang, H. H., Mao, Z. T., Li, T. M., Li, W., and Wu, H. Q. (2018b). Clinical Observation of Dendrobium Officinale in Mount Longhu in the Treatment of Hypertension. Clin. J. Trad. Chin. Med. 30, 297-300. doi:10.16448/ j.cjtcm.2018.0088

Wu, J., Zhuang, H. H., Mao, Z. T., Li, T. M., Li, W., and Wu, H. Q. (2017). Comparison of the Clinical Efficacy of Dendrobium Officinale in Mount Longhu in the Treatment of Type 2 Diabetes Mellitus. Jiangxi. J. Trad. Chin. Med. 48, 45-47.

Wu, Y. L., Huang, S. H., He, C. M., Qiu, B., Liu, J. J., Li, J., et al. (2020). Dendrobium Officinale Flower Extraction Mitigates Alcohol-Induced Liver Injury in Mice: Role of Anti-steatosis, Anti-oxidative, and Anti-inflammatory. Evid. Based. Complement. Alternat. Med. 2020, 1421853-1421864. doi:10.1155/2020/ 1421853 
Xiao, X. C., Chen, W. H., Cao, Y. Y., Lou, Y. J., Liu, Y., Wang, J., et al. (2018). Protective Effect of Dendrobium Officinale on Isoproterenol Induced Cardiac Hypertrophy in Rats. China. J. Chin. Mater. Med. 43, 800-804. doi:10.19540/ j.cnki.cjcmm.2018.0021

Xing, S., Yu, W., Zhang, X., Luo, Y., Lei, Z., Huang, D., et al. (2018). Isoviolanthin Extracted from Dendrobium Officinale Reverses TGF-B1-Mediated EpithelialMesenchymal Transition in Hepatocellular Carcinoma Cells via Deactivating the TGF- $\beta /$ Smad and PI3K/Akt/mTOR Signaling Pathways. Ijms 19, 1556-1572. doi:10.3390/ijms19061556

Xu, Z., Li, L., Xu, Y., Wang, S., Zhang, X., Tang, T., et al. (2021). Pesticide multiresidues in Dendrobium officinale Kimura et Migo: Method validation, residue levels and dietary exposure risk assessment. Food Chem. 343, 128490-128517. doi:10.1016/j.foodchem.2020.128490

Yan, M. Q., Su, J., Yu, J. J., Yang, Z. Y., Wang, T., Chen, S. H., et al. (2019a). [Effects and Active Substances of Ethanol Extract from Dendrobium Officinale on Metabolic Hypertensive Rats Induced by Comprehensive Dietary]. Zhongguo Zhong Yao Za Zhi 44, 4896-4904. doi:10.19540/j.cnki.cjcmm.20190610.401

Yan, M. Q., Yang, Z. Y., Shi, Q. Q., Wang, T., Chen, S. H., and Lv, G. Y. (2019b). Research Progress on Protective Effects and Mechanism of Dendrobium Officinale on Metabolic Disturbances. Chin. Trad. Herb. Drug 50, 2491-2497. doi:10.7501/j.issn.0253-2670.2019.10.033

Yang, K., Lu, T., Zhan, L., Zhou, C., Zhang, N., Lei, S., et al. (2020). Physicochemical Characterization of Polysaccharide from the Leaf of Dendrobium Officinale and Effect on LPS Induced Damage in GES-1 Cell. Int. J. Biol. Macromolecules 149, 320-330. doi:10.1016/j.ijbiomac.2020.01.026

Ye, Z., Dai, J. R., Zhang, C. G., Lu, Y., Wu, L. L., Gong, A. G. W., et al. (2017). Chemical Differentiation of Dendrobium Officinale and Dendrobium Devonianum by Using HPLC Fingerprints, HPLC-ESI-MS, and HPTLC Analyses. Evid. Based. Complement. Alternat. Med. 2017, 8647212-8647219. doi:10.1155/2017/8647212

Yu, Q. X., Guo, Y. Y., Si, J. P., Wu, L. S., and Wang, L. H. (2014). [Variation of Polysaccharides and Alcohol-Soluble Extracts Content of Dendrobium Officinale]. Zhongguo Zhong Yao Za Zhi 39, 4769-4772. doi:10.4268/cjcmm20142414

Yu, Z., Liao, Y., Teixeira da Silva, J., Yang, Z., and Duan, J. (2018). Differential Accumulation of Anthocyanins in Dendrobium Officinale Stems with Red and green Peels. Ijms 19, 2857-2870. doi:10.3390/ijms19102857

Yue, H., Liu, Y., Qu, H., and Ding, K. (2017). Structure Analysis of a Novel Heteroxylan from the Stem of Dendrobium Officinale and Anti-angiogenesis Activities of its Sulfated Derivative. Int. J. Biol. Macromolecules 103, 533-542. doi:10.1016/j.ijbiomac.2017.05.097

Zeng, J., Li, D., Li, Z., Zhang, J., and Zhao, X. (2020). Dendrobium Officinale Attenuates Myocardial Fibrosis via Inhibiting EMT Signaling Pathway in HFD/ STZ-induced Diabetic Mice. Biol. Pharm. Bull. 43, 864-872. doi:10.1248/ bpb.b19-01073

Zhang, J.-y., Guo, Y., Si, J.-p., Sun, X.-b., Sun, G.-b., and Liu, J.-j. (2017a). A Polysaccharide of Dendrobium Officinale Ameliorates H2O2-Induced Apoptosis in H9c2 Cardiomyocytes via PI3K/AKT and MAPK Pathways. Int. J. Biol. Macromolecules 104, 1-10. doi:10.1016/j.ijbiomac.2017.05.169

Zhang, X., Zhang, S., Gao, B., Qian, Z., Liu, J., Wu, S., et al. (2019). Identification and Quantitative Analysis of Phenolic Glycosides with Antioxidant Activity in Methanolic Extract of Dendrobium Catenatum Flowers and Selection of Quality Control Herb-Markers. Food Res. Int. 123, 732-745. doi:10.1016/ j.foodres.2019.05.040

Zhang, Y., Wu, Z., Liu, J., Zheng, Z., Li, Q., Wang, H., et al. (2020). Identification of the Core Active Structure of a Dendrobium Officinale Polysaccharide and its Protective Effect against Dextran Sulfate Sodium-Induced Colitis via Alleviating Gut Microbiota Dysbiosis. Food Res. Int. 137, 109641-109652. doi:10.1016/j.foodres.2020.109641

Zhang, Y., Zhang, L., Liu, J., Liang, J., Si, J., and Wu, S. (2017b). Dendrobium Officinale Leaves as a New Antioxidant Source. J. Funct. Foods 37, 400-415. doi:10.1016/j.jff.2017.08.006

Zhang, Z., Zhang, D., Dou, M., Li, Z., Zhang, J., and Zhao, X. (2016). Dendrobium officinale Kimura et Migo attenuates diabetic cardiomyopathy through inhibiting oxidative stress, inflammation and fibrosis in streptozotocininduced mice. Biomed. Pharmacother. 84, 1350-1358. doi:10.1016/ j.biopha.2016.10.074

Zhao, G.-Y., Deng, B.-W., Zhang, C.-Y., Cui, Y.-D., Bi, J.-Y., and Zhang, G.-G. (2018a). New Phenanthrene and 9, 10-dihydrophenanthrene Derivatives from the Stems of Dendrobium Officinale with Their Cytotoxic Activities. J. Nat. Med. 72, 246-251. doi:10.1007/s11418-017-1141-2

Zhao, M., and Han, J. (2018b). Dendrobium officinale Kimura et Migo ameliorates insulin resistance in rats with diabetic nephropathy. Med. Sci. Monit. Basic Res. 24, 84-92. doi:10.12659/msmbr.909242

Zhao, M., Sun, Y., Gao, Z., Cui, H., Chen, J., Wang, M., et al. (2020). Gigantol Attenuates the Metastasis of Human Bladder Cancer Cells, Possibly through Wnt/EMT Signaling. Ott Vol. 13, 11337-11346. doi:10.2147/ott.s271032

Zhao, X., Dou, M., Zhang, Z., Zhang, D., and Huang, C. (2017). Protective Effect of Dendrobium Officinale Polysaccharides on H2O2-Induced Injury in H9c2 Cardiomyocytes. Biomed. Pharmacother. 94, 72-78. doi:10.1016/ j.biopha.2017.07.096

Zhao, Y., Li, B., Wang, G., Ge, S., Lan, X., Xu, G., et al. (2019). Dendrobium Officinale Polysaccharides Inhibit 1-Methyl-2-Nitro-1-Nitrosoguanidine Induced Precancerous Lesions of Gastric Cancer in Rats through Regulating Wnt/ $\beta$-Catenin Pathway and Altering Serum Endogenous Metabolites. Molecules 24, 2660-2673. doi:10.3390/molecules 24142660

Zheng, H., Pan, L., Xu, P., Zhu, J., Wang, R., Zhu, W., et al. (2017). An NMR-Based Metabolomic Approach to Unravel the Preventive Effect of Water-Soluble Extract from Dendrobium Officinale Kimura \& Migo on StreptozotocinInduced Diabetes in Mice. Molecules 22, 1543-1556. doi:10.3390/ molecules 22091543

Zhou, C. H., Xie, Z. S., Lei, Z. X., Huang, Y. C., and Wei, G. (2018). Simultaneous Identification and Determination of Flavonoids in Dendrobium Officinale. Chem. Cent. J. 12, 40-48. doi:10.1186/s13065-018-0403-8

Zhu, B., Wu, L. S., Wan, H. T., Yang, K., Si, J. P., and Qin, L. P. (2018). Fungal Elicitors Stimulate Biomass and Active Ingredients Accumulation in Dendrobium Officinale Plantlets. China. J. Chin. Mater. Med. 73, 1-10. doi:10.2478/s11756-018-0091-9

Zhu, L.-J., Wang, M.-Q., Qin, Y., Wang, M.-N., Zhang, G.-Q., Niu, L.-T., et al. (2020). Two New Dibenzyl Derivatives from the Stems of Dendrobium Catenatum. J. Asian Nat. Prod. Res. 2020, 1-6. doi:10.1080/ 10286020.2020.1826937

Zhu, Q., Sheng, Y., Li, W., Wang, J., Ma, Y., Du, B., et al. (2019). Erianin, a Novel Dibenzyl Compound in Dendrobium Extract, Inhibits Bladder Cancer Cell Growth via the Mitochondrial Apoptosis and JNK Pathways. Toxicol. Appl. Pharmacol. 371, 41-54. doi:10.1016/j.taap.2019.03.027

Zuo, S.-M., Yu, H.-D., Zhang, W., Zhong, Q., Chen, W., Chen, W., et al. (2020). Comparative Metabolomic Analysis of Dendrobium Officinale under Different Cultivation Substrates. Metabolites 10, 325-338. doi:10.3390/metabo10080325

Conflict of Interest: The authors declare that the research was conducted in the absence of any commercial or financial relationships that could be construed as a potential conflict of interest.

Publisher's Note: All claims expressed in this article are solely those of the authors and do not necessarily represent those of their affiliated organizations, or those of the publisher, the editors and the reviewers. Any product that may be evaluated in this article, or claim that may be made by its manufacturer, is not guaranteed or endorsed by the publisher.

Copyright (C) 2021 Chen, Lu, Zhang, Wu, Yu, Qin and Zhu. This is an open-access article distributed under the terms of the Creative Commons Attribution License (CC $B Y)$. The use, distribution or reproduction in other forums is permitted, provided the original author(s) and the copyright owner(s) are credited and that the original publication in this journal is cited, in accordance with accepted academic practice. No use, distribution or reproduction is permitted which does not comply with these terms. 


\section{GLOSSARY}

D. officinale Dendrobium officinale

HPLC high performance liquid chromatography

HPAEC high performance gel permeation chromatography

GC-MS gas chromatography-mass spectrometry

GPC gel permeation chromatography

HPLC-ESI-MS high performance liquid chromatography electrospray ionization mass spectrometry

UHPLC ultra-high performance liquid chromatography

QTOF quadrupole time of flight mass spectrometry

ISO isoproterenol

ANP atrial natriuretic peptide

BNP brain natriuretic peptide

cTN-I cardiac troponin I

LAD anterior descending coronary artery

CK creatine kinase

LDH lactate dehydrogenase

MDA malondialdehyde

SOD superoxide dismutase

H2O2 hydrogen peroxide

PI3K phosphatidylinositol

Akt protein kinase B

MAPK mitogen-activited protein kinase

LPD lipid peroxidation damage

ROS reactive oxygen species

HMEC-1 human microvascular endothelial cells

DOFP D. officinale ultrafine powder

LPS lipopolysaccharide

TLR4 toll-like receptor 4

TC total cholesterol

TG triglyceride

LDL-c low-density lipoprotein cholesterol

CRP C-reactive protein

IL-6 interleukin 6

MyD88 myeloid differentiation factor

TNF- $\boldsymbol{\alpha}$ tumor necrosis factor alpha

HDL-c high-density lipoprotein cholesterol

NO nitric oxide

ET-1 endothelin 1

TXB2 thromboxane B2

PGI2 prostacycline

SCFA short-chain fatty acid

ACHSFD alcohol, and high sugar and fat diets
MNNG methyl-2-nitro-1-nitrosoguanidine

EMT epithelial-mesenchymal transition

HNSCC human head and neck squamous carcinoma cells

JNK jun N-terminal kinase

NPC nasopharyngeal carcinoma

TGF transforming growth factor

HCC hepatocellular carcinoma

SAR structure-activity relationship

AMPK AMP-activated protein kinase

LC-3 $\beta$ light chain $3 \beta$

HO-1 heme oxygenase-1

HFD/STZ high-fat diet/streptozotocin

TLRs toll-like receptors

DMBG dimethylbiguanide

VEGF vascular endothelial growth factor

GLUT-1 glucose transporter 1

CTGF connective tissue growth factor

IgM immunoglobulin $\mathrm{M}$

NF-кB, nuclear factor kappa-B

GSH-Px glutathione peroxidase

T-AOC total antioxidant capacity

DOP D. officinale polysaccharide

LOD lipid oxidation

OVX ovariectomy

ALP alkaline phosphatase

BGP bone glucose protein

ACP acid phosphatase

BMD bone mineral density

RANKL receptor activator expression of the nuclear factor- $\kappa B$ ligand

Nrf2 nuclear factor E2-related factor 2

KCC2 $\mathrm{K}+-\mathrm{Cl}$-cotransporter 2

HIF-1 $\alpha$ hypoxia-inducible factor-1 $\alpha$

HDAC1 Histone deacetylase 1

HIBD hypoxic-ischemic brain damage

TBARS thiobarbituric acid reactive substances

MUC5AC mucin-5AC

ABEE aminobenzoic acid ethyl ester

RSD relative standard deviation

PCA principal component analysis

HC hierarchical cluster analysis

NHFPC national health and family planning commission

PR people's republic 